\title{
THE INFLUENCE OF CULTURE ON CHILDREN'S RELATIONSHIPS WITH NATURE
}

\author{
by \\ Andrea Donnell \\ Honours Diploma, Early Childhood Education \\ George Brown College, 2010 \\ Honours Bachelor of Arts, Major in Early Childhood Education \\ Ryerson University, 2012
}

\author{
A Major Research Paper \\ presented to Ryerson University \\ in partial fulfillment of the \\ requirements for the degree of \\ Master of Arts \\ in the Program of \\ Early Childhood Studies \\ Toronto, Ontario, Canada, 2013
}

(C)Andrea Donnell 2013 


\section{Author's Declaration}

I hereby declare that I am the sole author of this MRP. This is a true copy of the MRP, including any required final revisions.

I authorize Ryerson University to lend this MRP to other institutions or individuals for the purpose of scholarly research

I further authorize Ryerson University to reproduce this MRP by photocopying or by other means, in total or in part, at the request of other institutions or individuals for the purpose of scholarly research.

I understand that my MRP may be made electronically available to the public. 
The Influence of Culture on Children's Relationships with Nature

(C) Andrea Donnell 2013

\author{
Master of Arts \\ Early Childhood Studies \\ Ryerson University
}

\begin{abstract}
This mixed-method study compared 5 to 8 years old children from Canada and Slovakia and their relationship with nature. A total of 52 children participated in this study; more specifically, 26 children from Toronto, Canada and 26 children from Bratislava, Slovakia. The children's relationship with nature was examined through understanding their definition of nature, experiences in and feelings towards nature. Children illustrated a picture of nature and their activities in it. They then participated in semi-structured interview and lastly participated in a dialogue about photographs of nature. The 'new sociology of childhood' and 'universalism in cross-cultural psychology' theoretical frameworks were used to frame this study. The results revealed that there were no cultural differences in the children's relationship with nature; however, cultural differences were apparent in the way children constructed their relationship. Children from both countries exhibited positive feelings towards nature, but the way they engaged with it was culturally different. Therefore, culture plays a role when establishing a connection with nature. Recognizing that children from various cultural backgrounds enjoy being in nature and acknowledging nature's positive effects on their overall well-being can help guide parents, caregivers, educators and policy makers to work together to ensure children can reap the benefits of nature for their healthy development.
\end{abstract}

Keywords: Children, nature, culture, relationship, connection, natural environment 


\section{Acknowledgements}

First, I would like to thank to my MRP supervisor, Dr. Robert Rinkoff. I feel grateful for all the guidance, patience, time and dedication in helping me to succeed. Your academic expertise, patience and refreshing sense of humour made this challenging task much more manageable. I cannot thank you enough for continuously challenging me, especially when defining 'nature.' The biggest thank you is for believing that I could accomplish this complex study within a short period of time.

I would like to thank my second reader, Dr. Patricia Corson. Your encouragements and expertise on culture development gave me a strong foundation for this study.

A respectful thank you goes to the chair of the oral examination, Dr. Mehrunnisa Ali. Your tremendous support, valuable feedbacks and continuously challenging my work over the year helped me to academically grow.

I also would like to thank all children who participated in the study. Without you, this study would not be possible.

I would like to thank to my husband, Steve. I deeply appreciate all the support, patience and encouragement to persevere. In addition to your career and life challenges, you shouldered the extra weight when things got tougher. Thank you for believing in me. This accomplishment is much as yours as mine.

I would like to thank to my parents, Eva and Igor, for their never-ending support, encouragement, and faith in me. Your assistance during the research process is invaluable. Without you, I would not be where I am. 
I also would like to thank ECS graduate faculty, Dr. Aurelia Di Santo, Dr. Kathryn Underwood, Dr. Marni Binder and Dr. Rachel Berman, for providing me with valuable feedback during my studies.

Lastly, thank you goes to all my family, friends and colleagues for their ongoing support and help. 


\section{Dedication}

I dedicate this research to my husband, Steve, as through his difficult time of losing his father he still was able to give me much needed support. I also would like to dedicate this study to my parents, Eva and Igor, for they made me what I am today. 


\section{Table of Contents}

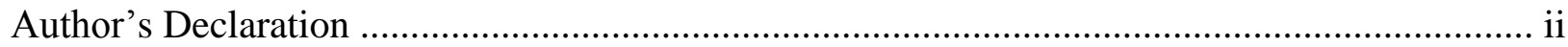

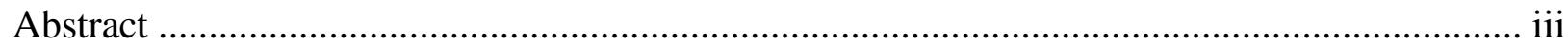

Acknowledgments .......................................................................................................... iv

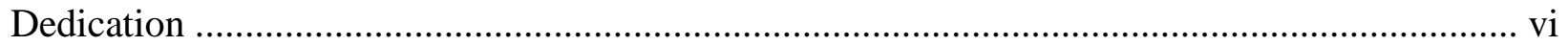

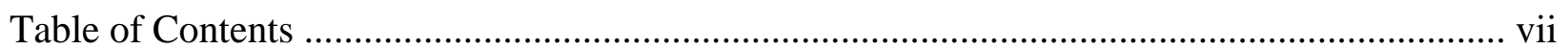

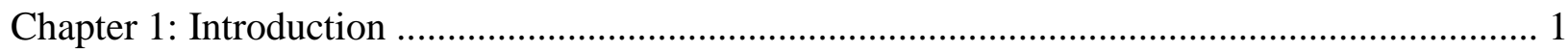

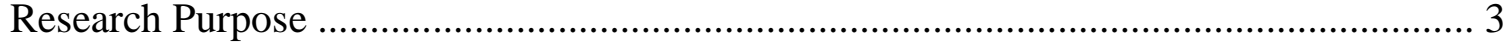

Research Questions and Sub-Questions........................................................................ 3

Research Hypotheses .......................................................................................... 3

Conceptual Framework ............................................................................................... 4

The Theory of the New Sociology of Childhood .................................................. 4

Universalism in Cross-Cultural Psychology …………........................................... 5

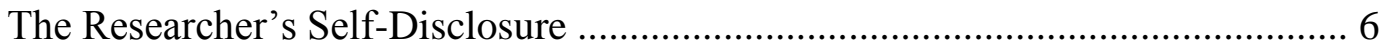

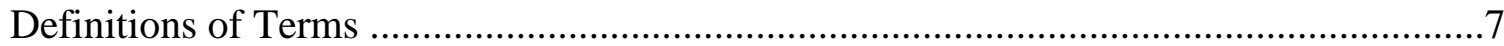

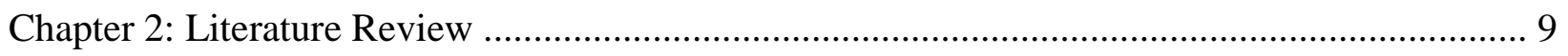

Children-Nature Connection .................................................................................... 9

Children's Feelings and Attitudes towards Nature ………………………………...... 12

Children's Experiences in Nature ........................................................................... 15

Barriers to Children's Exploration of Nature …………………................................. 18

Chapter 3: Methodology …………………………………………………………….... 22

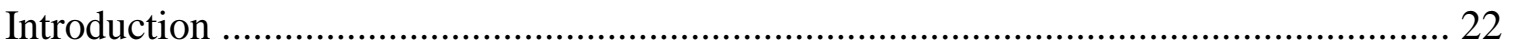

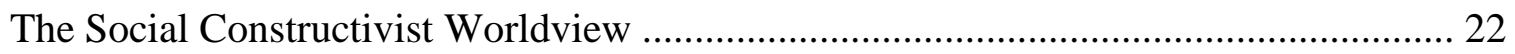

The Mixed Method Approach ........................................................................................ 23

The Qualitative Research Method .......................................................................... 23

The Grounded Theory Research Strategy …………………………………...... 24

The Quantitative Research Method .............................................................. 25

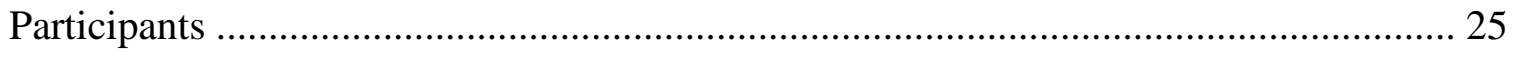

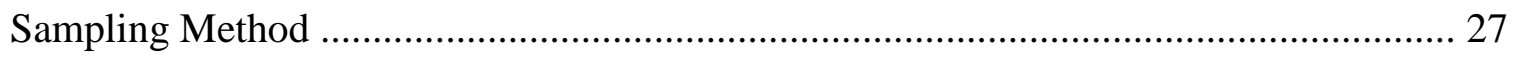

Recruitment of Participants ................................................................................... 27

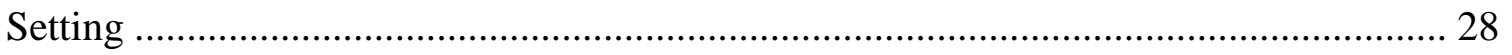




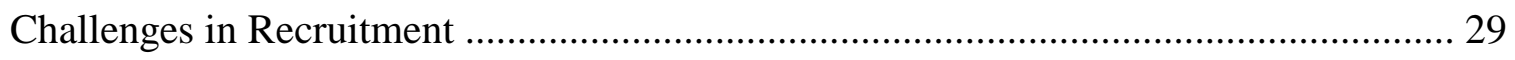

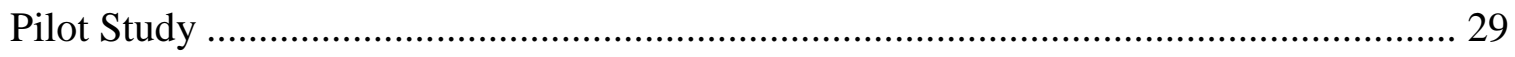

Data Collection Process and Tools ............................................................................... 30

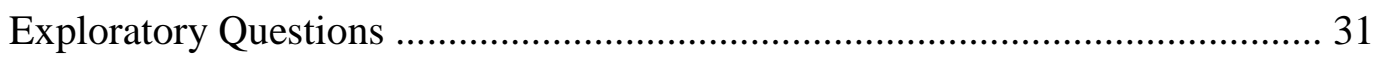

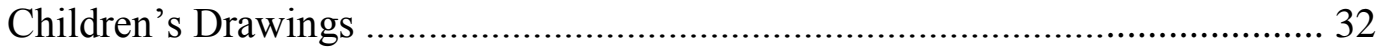

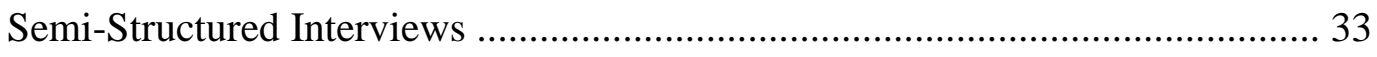

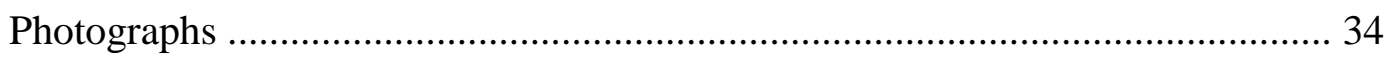

Data Recording Procedures ………………………….............................................. 35

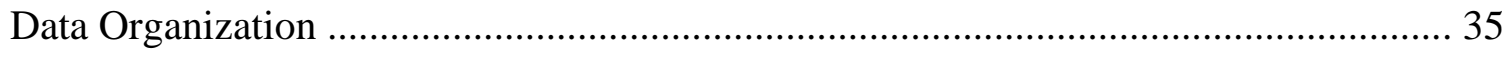

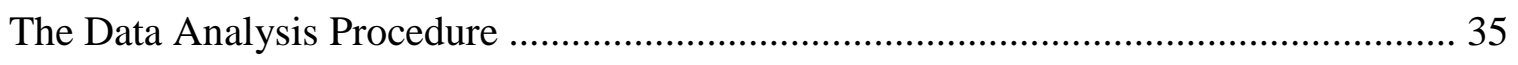

The Qualitative Data Analysis Procedure ……………......................................... 36

The Quantitative Data Analysis Procedure …………............................................ 37

Validity, Reliability and Qualitative Rigour ....................................................... 38

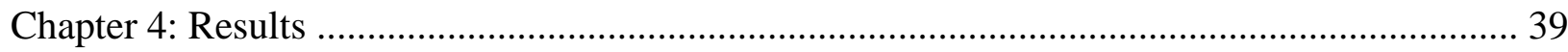

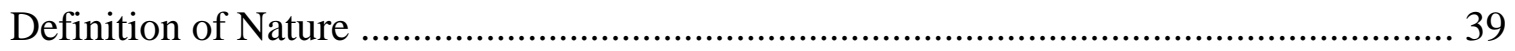

Additional Findings about Children's Definition of Nature ……......................... 40

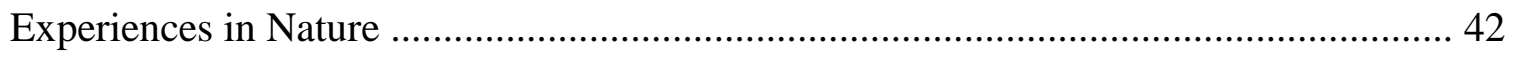

Children's Feelings towards Nature ……………………....................................... 46

Additional Findings about Children's Feelings ................................................... 49

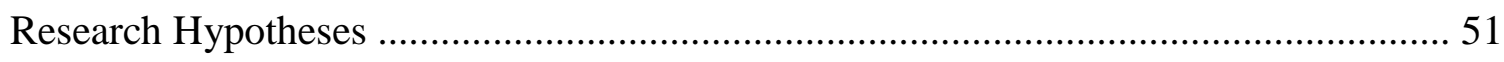

$\mathrm{H}_{1}$ : Direct Experiences with Nature in Children's Drawings ................................ 51

$\mathrm{H}_{2}$ : Natural Elements in Children's Drawings ................................................... 52

Additional Findings from Children's Drawings ………………………………....... 53

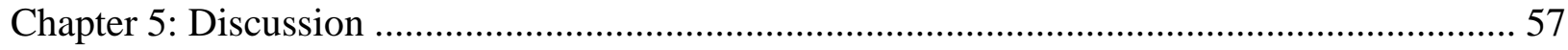

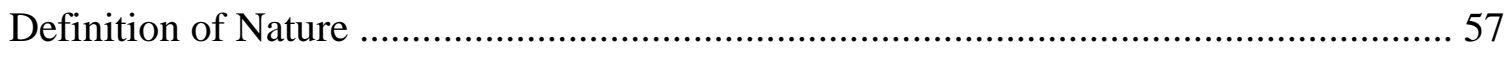

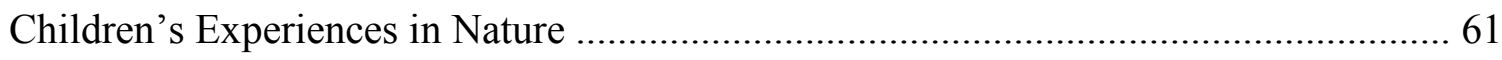

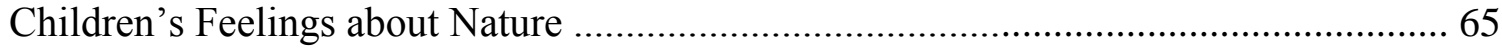

$\mathrm{H}_{1:}$ Children's Drawings of Direct Experiences in Nature ..............................................6 68

$\mathrm{H}_{2}$ : Natural Elements in Children's Drawings ……………........................................ 69

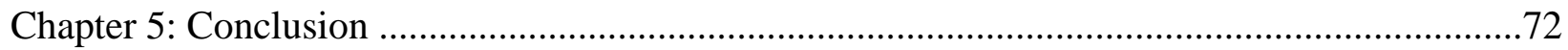

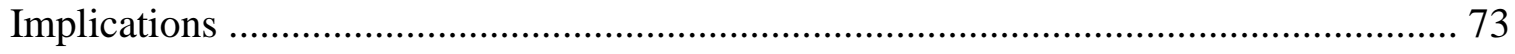


Limitations of the Study and Future Research ...................................................... 73

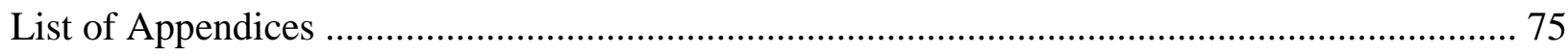

Appendix A: Parental Recruitment Information ................................................. 75

Appendix B: Parental Consent Agreement................................................................ 77

Appendix C: Child Assent Agreement ...................................................................... 80

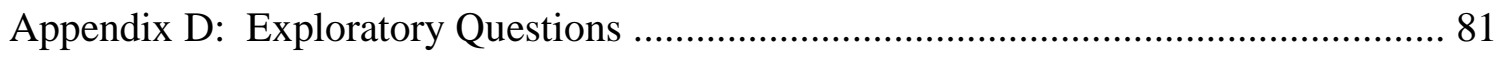

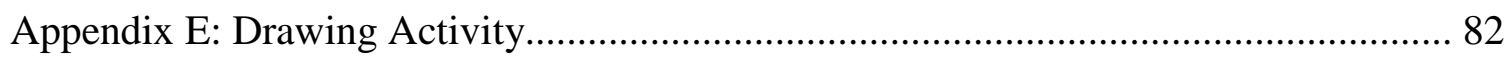

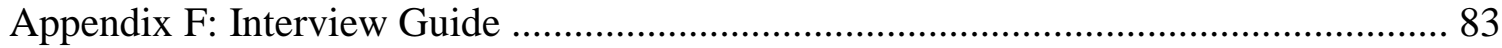

Appendix G: Interview Guide: Photographs of Nature ........................................... 84

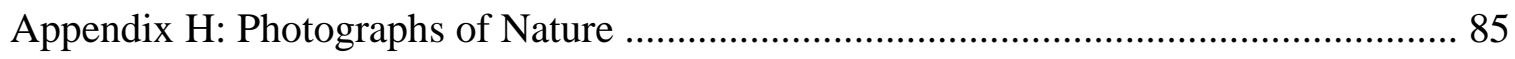

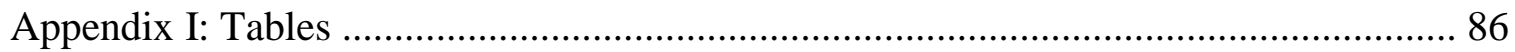

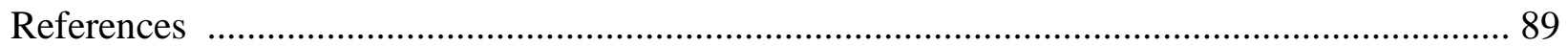




\title{
CHAPTER 1: INTRODUCTION
}

\author{
Nature - "Stuff that helps us, like, live" (Steve, 8, Canada).
}

The positive effect of nature on people's overall well-being has been well documented.

Nature has a restorative psychological and emotional health benefit (Berger, \& McLeod, 2006;

Harting, Kaiser, \& Strumse, 2007; Ulrich, 1984). Time spent in nature has been linked with improved cognitive functioning (Berman et al., 2012), reduced Attention Deficit Hyperactivity Disorder (ADHD) symptoms (Faber Taylor, Kuo, \& Sullivan, 2001), improved concentration (Faber Taylor, \& Kuo, 2006), better motor skills (Fjørtoft, 2001) and enhanced self-esteem (Maller, 2009). Children who are not given the opportunity to have direct experiences with nature are significantly disadvantaged and deprived of the health benefits that nature provides. In order to reap the benefits of nature and natural environments, children need to have direct experiences with nature (Chawla, \& Hart, 1995; Kellert, 2005).

Most contemporary theorists acknowledge that the cognitive development of a child is formed by social and environmental milieu (Miller, 2011), thus, pattern of cognitive development are not universal (Penn, 2008). Cross-cultural studies allow psychologists and cultural researchers to understand the variations in children's development across cultures. Researchers are able to examine whether behaviors are culture-bound or are the same across cultures (Gardiner, \& Kosmitzki, 2011). In addition, cross-cultural research serves "to refine and expand the usefulness of several theories" (Gardiner, \& Kosmitzki, 2011, p. 9). According to Flavell, Miller, \& Miller (2002), emotions are socially constructed. It is the culture that shapes how children "define, categorize, and label emotions" (Flawell, Miller, \& Miller, 2002, p. 212). The authors state that different cultures may have different attitudes towards nature. Kellert (1996) indicates that the development of values concerning nature changes across age groups, with the most dramatic shift beginnings approximately around the age of six years old. 
Many researchers are suggesting that contemporary children are spending less time in nature than any previous generation (Clements, 2004; Jackson, \& Tester, 2008; Louv, 2005), thus children's direct experiences with nature have started to decline (Charles, Louv, Bodner, Guns, \& Stahl, 2009; Kellert, 2005). Louv (2005) suggests that today's children in the U.S. and Canada have very few experiences in and with nature. Scholars claim that the lack of available natural spaces in urban areas is the reason why children have moved indoors (Driessnack, 2009; Faber-Taylor, \& Kuo, 2006; Pergams, \& Zaradic, 2006). Others point to inventions like the television, computer and video games for the disconnection between children and nature (Louv, 2005; Roberts, \& Foehr, 2008).

Previous research examining relationships with nature tends to explore only a few facets. Firstly, there are a limited number of recent studies exploring cross-cultural children's relationships with nature. Secondly, the majority of research that has been done focuses on older children (e.g., Aaron, \& Witt, 2011), youths (e.g., Boeve-De Pauw, \& Van Petegem, 2012) and adults (e.g., Mayer, \& Frantz, 2004). Whether young children in different countries have similar or different relationships with nature has remained a topic to be further explored.

To fill this gap in the research, this study compared the similarities and differences of young children's relationships and experiences with nature in two different countries: Canada and Slovakia. This is significant, as cultural similarities and differences help to explain whether a child's relationship with nature is culturally bound. In this study, young children's definitions, attitudes and experiences in nature were explored.

The findings from this research can help professionals in early childhood studies to better understand how some children from different cultures develop and why they behave differently. Specifically, the cross-cultural variations in a child's relationship with nature provide researchers 
and educators with insight into how children from different countries interact with nature and why. Acknowledging these patterns, educators, curriculum planners and policy makers can better tailor educational experiences for children in nature.

\section{Research Purpose}

The purpose of this study was to compare 5 to 8 year old children from two different regions of the world and their relationships with nature. The study investigated how children define nature as well as their attitudes towards it and experiences in and with it. At this point nature is defined as all living and non-living things that originate on planet Earth naturally (Nature, 1996). A detailed definition will be discussed in the definitions of terms section.

\section{Research Question and Sub-Questions}

The research question, “What are children's relationships with nature in Canada in comparison to children in Slovakia" is further explored by the following sub-questions:

1. How do children from Canada define nature in comparison to children from Slovakia?

2. What kinds of experiences in nature do children living in Canada have compared to children living in Slovakia?

3. What are children's attitudes towards nature in Canada in comparison to children in Slovakia? What do the children in the two countries like and dislike about nature? A mixed method data collection procedure was employed to answer these questions. It provided opportunities to understand the participants' viewpoint about nature and further illustrate the findings numerically. This approach allowed participants to be active during the research process and provided opportunities for their voices to be heard (Leitch, 2008).

\section{Research Hypotheses}

Based on the previous research suggesting that there are cultural differences in people's relationship with nature, it is hypothesized: 
$\mathrm{H}_{1}$ : There will be differences between children from Canada and Slovakia regarding the number of children drawing direct experiences with nature.

$\mathrm{H}_{2}$ : There will be differences in the number of different identifiable types of natural elements in the Canadian and Slovakian children's drawings.

\section{Conceptual Framework}

\section{The Theory of the New Sociology of Childhood}

The theory of the new sociology of childhood is used to frame and analyze this study. The new sociology of childhood views children as social actors who actively participate in the construction of their lives and the society they live in (Matthews, 2007). The framework considers the children's viewpoint as an important source for understanding phenomena from the child's perspective. Children are viewed as competent and knowledgeable human beings (Smith, Duncan, \& Marshall, 2005). The new sociology of childhood views children as active agents in their societies and moves beyond just adult socialization (Matthews, 2007).

The new sociology of childhood has its roots in the United Nations Convention on the Rights of the Child (UNCRC) (1989). The UNCRC (1989), particularly Article 13, stipulates that children have the rights to freely express their opinion. Additionally, Article 12 in the UNCRC (1989) recognizes that children are capable of expressing their views about affairs that affect their lives. "Childhood and children are therefore seen as worthy of investigation in their own right, separate from their parents or caregivers" (Einarsdóttir, 2007, p.198). Researchers listening to children's voices thus acknowledge the human rights of children.

The new sociology of childhood acknowledges that children in different cultures and societies develop different childhoods (Matthews, 2007). These experiences vary depending on the setting. Children construct different knowledge in different contexts. Research in non- 
Western cultures expands the knowledge of diversity among children and childhoods (Matthews, 2007). Hence, childhood experiences must be rooted in the child's social context rather than being generalized and made applicable to all children (Matthews, 2007).

The way this framework views children's roles within their societies reflects my belief that children are active and competent individuals within their culture. Utilising the new sociology of childhood allowed me to examine the relationship children have with nature from their perspective. Children were able to interpret their attitudes, perceptions and experiences in nature, thus providing me with rich and descriptive data rooted in the children's experiences in given contexts, namely Canada and Slovakia.

\section{Universalism in Cross-Cultural Psychology}

Another framework used in the study was universalism in the field of cross-cultural psychology (Berry, Poortinga, Breugelmans, Chasiotis, \& Sam, 2011). Cross-cultural psychology is the study of human behaviour that is influenced by culture (Berry et al., 2011). It explores the similarities and differences in humans' behaviour in diverse cultural settings. More

precisely, cross-cultural psychology investigates the relationships between behaviour and culture. Universalism presumes that basic psychological process are universal (e.g., feeling, perceiving); however, the way in which processes (e.g., attitudes, values) manifest is different in different cultures (Berry et al., 2011). The authors define culture as "the shared way of life of a group of people” (Berry et al., 2011, p.4).

Universalism aligns with my belief that children have emotions relating to nature, but their values and attitudes develop differently in different cultures. Employing universalism in cross-cultural psychology permitted me to examine children's connections with nature in two 
countries. It allowed me to compare the similarities and differences in the relationship children have with nature in Canada and Slovakia.

\section{The Researcher's Self-Disclosure}

In qualitative research, the researcher is the primary instrument of collecting data. Personal and professional experiences influence the researcher's methodological choices (Creswell, 2009). My interest in the relationships children have with nature in different cultures has been shaped by my personal and professional experiences. I was born and raised in Slovakia where my passion for nature and natural environments was formed. From a very early age, nature explorations were part of my growing up. My family played an important role in guiding and modeling my nature experiences; however, these experiences have been further developed by my propensity for natural environments. My early experiences contributed to my positive attitude and perception about nature and this persists into my later life. I continually seek direct experiences in nature. I believe that these experiences have a positive impact on my overall wellbeing.

As an adult, I moved to Canada where I become a registered early childhood educator. During my career as an early childhood educator, I observed how young children engaged in outdoor play and interacted with nature. I noticed that children at schools, in childcare settings and in their homes spent a limited amount of time outdoors and in nature. As I compared these observations with my personal school and childcare recollections, I noticed that during my early learning years, institutions provided more opportunities to explore nature. These differences could be a result of societal changes or a difference in cultural context.

Disclosing my beliefs and assumptions about children and nature allows for a better understanding of my biases that shaped this research. The following are some of my assumptions 
about children and nature: I believe that for optimal child development, children need direct nature experiences. I am convinced that early encounters with natural environments shape a child's values and beliefs that are carried into adult life. I presume that children in industrial countries have few direct encounters with nature. I assume that children's relationships with nature are different across cultures.

My knowledge of child development and experiences with nature in different countries assisted me in developing the research question about children's relationships with nature. In order to prevent assumptions from interfering with the objectivity of the study, Fischer (2009) recommends bracketing. Bracketing refers to "identification of vested interests, personal experience, cultural factors, assumptions, and hunches that could influence how he or she views the study's data" (Fischer, 2009, p.583). I have identified the biases and experiences, which could influence my data analysis and interpretation. Bracketing allowed me to suspend my own attitudes and beliefs about the participants and the subject being investigated (Husserl, 18591938, as cited in Fischer, 2009).

\section{Definitions of Terms}

- Attitude is a cognitive disposition or feeling about an object or a person (Attitude, 1996) that ranges from positive to negative (Petty, Wegener, \& Fabrigar, 1997).

- Culture is difficult to define, as there is no agreed-upon definition. Gardiner and Kosmitzki (2011) define culture as a "cluster of learned and shared beliefs, values (...), practices (...), behaviors (...), symbols (...), and attitudes (...) that are characteristic of a particular group of people and that are communicated from one generation to another" (p.5). For the purpose of this research paper, culture refers to a country with a specific geographical location that has a distinct economic, political and social circumstance. 
- Direct Experiences in Nature refers to unstructured, spontaneous experiences and the way children engage and participate in and with nature. It includes hiking in a forest, swimming in a lake, climbing a tree, collecting artifacts from nature, gardening etc. Playing sports, riding a bike and looking at nature are considered to be indirect experiences with nature. This definition was adapted from Kellert (2005).

- Nature is a complex term. Webster's Dictionary (Nature, 1996) defines it as "the material world especially as surrounding humankind and existing independently of human activities (...) the elements of the natural world, as mountains, trees, animals or rivers" (p.1281). Therefore, nature is defined as encompassing all living and non-living things that originate on planet Earth naturally. For example: desserts, oceans, glaciers, grass, humans, trees, forests, jungles, meadows, volcanoes, wildlife, mountains, sand, and rocks. Nature is not human made.

- Relationship with nature is defined as a way in which humans are connected to and interact or engage with nature. 


\section{CHAPTER 2: LITERATURE REVIEW}

The purpose of this section is to provide a review of scholarly literature relating to children's relationships with nature, with the focus on cross-cultural comparison. Cross-cultural comparisons of children's affiliations with nature is an emerging topic; therefore, multiple different empirical and conceptual works have been reviewed. This chapter reviews children's connections with nature, their feelings and attitudes towards nature, as well as their experiences and barriers in engagement with nature.

\section{Children-Nature Connection}

Research indicates that participation in a natural setting during childhood is especially important for the formation of attitudes that are carried into adulthood (Wells, \& Lekies, 2006). Numerous scholars indicate that contemporary children's experiences with nature are declining (Charles, Louv, Bodner, Guns, and Stahl, 2009; Clements, 2004, Kellert, 2005). Richard Louv (2005), writer of the book "Last Child in the Woods: Saving Our Children from Nature Deficit Disorder" forewarned that children are being disconnected from nature. The pinnacle of this finding was the statement made by a fourth-grader Paul from San Diego: "I like to play indoors better, 'cause that's where all the electrical outlets are" (Louv, 2005, p.10). Although, the disconnection from nature has not been specifically studied, there are scholarly articles that demonstrate the link between children's indoor activities and childhood obesity. In Canada, childhood obesity increased almost three times in the last 30 years (Healthy Canadians, 2013), coinciding with the explosion of electronic media.

Kellert and Wilson (1993) in their book The Biophilia Hypothesis, explained the human desire to relate to the natural environment. Wilson (1984) believes that our affinity to connect with the natural world is innate, although, the connection with nature, in many instances, is 
developed through social interaction with other people (Clayton, \& Myers, 2009). In their small quantitative study, Unsworth et al. (2012) compared 5 to 7 year-old Menominee Native American children to 5 to 7 year-old European American children's concept of nature. The authors found that the concept of nature is influenced by culture. Contrary to the 2012 study by Unsworth et al., Kahn (2002) in his cross-cultural research concluded that children's relationships with nature are similarly constructed across-different cultures. Kellert and Willson (1993) recognized that a human's natural tendency is to affiliate with life processes that lead to “individual meaning and personal fulfillment" (p.21), and self-motivation of protecting and caring for nature (Kellert, \& Willson, 1993).

Mayer and Frantz (2004) also recognized this and developed the Connectedness to Nature Scale (CNS) that measures adults' emotional relationship with the natural environment. The authors hypothesised that humans need to feel part of the natural environment in order to attend to environmental problems. The results support Mayer and Frantz's (2004) predictions that the nature connection is a predictor of environmental behaviour and that individual's well-being is related to the feeling of being connected to nature.

However, CNS has been criticized for not including a physical component of the humannature relationship. As a result, Nisbet, Zelenski and Murphy (2009) constructed the Nature Relatedness Scale (NRS). The scale examined the human connection with nature in three areas: experiential, affective and cognitive. A total of 831 Canadian undergraduate students filled in the NRS questionnaire. The more encompassing NRS highlighted a strong correlation between nature connectedness and the time spent in a natural environment. Similarly, a survey of fourthgrade students from the United Sates conducted by Cheng and Monroe (2012) confirmed that 
previous nature experiences strengthen children's connection with nature. However, the cultural variations in human-nature connection have not been examined.

Unlike the studies listed above measuring human-nature connection through using scales, Derr and Lance (2012) examined American children's connection with the natural world through participant observation. Fostering a connection with nature and children, according to Derr and Lance (2012), can be achieved through "biophilic design" (Kellert, 2008), which incorporates natural elements into urban environments (Kellert, 2008). Derr and Lance (2012) found that the type and characteristics of an environment provides different opportunities for play. While participant observation allowed researchers to observe children using the space, it did not allow them to understand why children used the particular space or how it was the same or different among children from different cultural backgrounds.

Children's connection with nature can also be investigated through examining the children's concept of nature (Samuelsson, \& Pramling, 2009). Swedish preschool children perceived nature as animals and plants (Samuelsson, \& Pramling, 2009). They were also able to recall specific details, such as identifying animal habitats and ecological processes like trees making oxygen (Samuelsson, \& Pramling, 2009).

These understandings are similar to those of adult science teachers in China in the Ma (2009) study. However, a few of these teachers also believed that some man-made artifacts are nature (Ma, 2009). Unlike teachers in Ma's (2009) research, students in Shepardson's (2005) study did not believe that man-made structures were natural environments. In total, 81 students from seventh through ninth grade in the United States participated in a draw-and-talk method study about their conception of the environment. Students were also shown seven photographs where they had to identify the picture as to whether it was a depiction of an environment or not. 
Participants indicated that natural landscapes without man-made structures are the environment (Shepardson, 2005).

The evidence listed above suggests that children, youth and adults are continuously constructing their conception of nature and thus developing a connection with nature. Their understanding of nature does not specify whether their relationship is positive or negative, but rather suggests that they are aware of nature.

\section{Children's Feelings and Attitudes towards Nature}

The way humans respond to their environment is through "perceiving its properties" (Clayton, \& Myers, 2009, p.74). Hyun (2005) claimed that experiences affect changes in the human brain. According to Shore (in Hyun, 2005), the human brain is dependent on "socialcultural environmental input" (p.202). In other words, the cognitive structures are influenced by the environmental experiences. Generally, people favour natural environments to non-natural settings (Kaplan, \& Kaplan, 2002). According to Kellert (2005) what makes a place significant is the result of a combination of nature and culture.

Currently, a consensus has not been reached among researchers as to whether emotions are culture-specific or universal (Berry et al., 2011). The lack of consensus is because scholars, on one side believe psychological processes (e.g., feelings) are similar but the behavioural expressions (e.g., attitudes) are different (Berry et al., 2011). On the other side, scholars argue that psychological processes are also different cross-culturally. Berry et al. (2011) conclude that emotions are, generally universal across cultures; however, some cultural variations were apparent. The differences were primarily a result of whether the expression of emotions was culturally acceptable or unacceptable (Lewis, \& Ozaki, 2009) and whether the emotional words were culturally specific (Berry et al., 2011). 
There is a limited amount of scholarly literature about cross-cultural research on children's feelings towards nature, as most of the research focus on children's environmental knowledge or attitude. Kellert (2005) recognized that children's feelings towards nature are constructed through their experiences with nature, which are influenced by a natural curiosity and a propensity to learn. Confirming this statement, Hougie (2010) found that children preferred playing in woodlands, exploring the rivers and building hideouts. Walking in the county side with no purpose, playing with a ball or walking a dog, children found boring (Hougie, 2010).

The positive feelings towards nature were identified by Strife (2008) who interviewed 50 children in grade five with varying socioeconomic status in three different schools in Denver, U.S.A. In addition to the interview, map making, drawing pictures and neighbourhood tours were employed to enhance the integrity of the study. The results revealed that children had a positive relationship with nature, as they commented feeling "happy," "free," and "peaceful" (Strife, 2008). The children's conception of nature was influenced by the location they lived in, as children from lower socioeconomic neighbourhoods reported seeing elements of nature such as "trees," "drain-pipes” and "tunnels" (Strife, 2008).

In addition to positive feelings towards nature, children also experience negative feelings towards the natural world (Heerwagen, \& Orians, 2002). Heerwagen and Orians (2002) explained that fears are developmental and some fears towards nature will change or dissipate with age. In their review of scholarly literature, they found that Angelino (as cited in Heerwagen, $\&$ Orians, 2002) concluded that fears of large animals diminish sometimes after 10 years of age. The fear of animals, such as snakes and spiders, is an evolutionary development of our species as some animals, at one point in time, were a danger to our existence (Clayton, \& Myers, 2009). Bixler and Floyd (1997) examined the reasons for children's negative feelings towards nature. 
They found that children from Texas reported feeling scared and disgusted towards wild land environments. These negative feelings correlate with children's preferences of an environment. Negative perceptions of wild lands correlated with a lower preference of an environment.

Kellert (2002) explained that young children hold negativistic values towards nature; this means that young children are afraid and avoid nature. The author further explained that these values change around the age of 6 years, where children start to avoid danger but focus to fulfill their needs. The developmental differences in changing attitudes towards nature were illustrated in Kalvaitis and Monhard's (2012) study. The authors investigated children's attitudes and relationships with nature across different ages. Children 6 to 11 years of age from a semi-rural elementary school in the Rocky Mountains, U.S.A. participated in a draw-and-write research study. The findings revealed that the children had positive attitudes towards nature, which were depicted through words such as "like" and "love" (Kalvaitis, \& Monhard, 2012, p.216). Furthermore, younger children were more likely to engage in activities, such as watching insects while older children participated in hiking activities. Children's positive attitudes could be related to their close proximity to the natural environment of mountains.

Kalvaitis and Monhard's (2012) study did not investigate whether attitudes were impacted by direct or indirect experiences with nature. Using longitudinal data collection, Duerden and Witt (2010) investigated the direct and indirect nature experiences and the impact on attitudes of youth in America. The findings revealed that direct experiences were more beneficial for attitude development than indirect. The participant's attitudes before the implementation of the program were examined only at the end of the study. This poses limitations, as participants had to reflect on their attitudes retrospectively, thus reports may not be accurate. 
Boeve-De Pauw and Van Petegem (2012) conclude that culture influences the environmental worldview of children. In their study, a total of 1586 children aged 13 to 15 years from Zimbabwe, Belgium and Vietnam filled in the questionnaire. The self-reported data indicate there are significant differences between the children in the environmental view. Even though children from all three countries hold an ecological perspective, where humans can have a negative impact on nature, Zimbabwean and Vietnamese children also hold a dominant view over nature because they feel entitled to impact nature negatively. Zimbabwean children perceived nature as able to restore itself, whereas, Vietnamese children perceived nature with limited resources. Although this study did not examine the values children hold towards nature, Boeve-De Pauw and Van Petegem's (2012) study illustrates that cross-cultural differences among children exists.

Similarly, culture influences children's awareness of environmental problems and their attitudes towards mitigating these issues (Aguirre-Bielschowsky, Freeman, and Vass, 2011). The qualitative study revealed that children aged 9-11 years from Mexico had a global perspective concerning environmental problems, while children of the same ages from New Zealand had a more local understanding. The authors conclude that culture could potentially influence how children construct their attitudes towards nature.

\section{Children's Experiences in Nature}

In 2010, in the "Reporting on the Pan Canadian Survey: Re Children and Nature," the park and recreation professionals reported that children and youth do not spend enough time in outdoor activities (Canadian Parks and Recreation, 2010). However, the results for this report were based on the perceptions of professionals working in the industry and not on the actual empirical measures of children's experiences. 
Kelert (2005) in his extensive work on children's experiences in nature contends that nature is important for healthy child development. Experiences with the natural world positively affect mental, physical and cognitive growth of children (Kellert, 2005). Kellert (2005) divides the nature encounters into three distinct categories: direct, indirect and vicarious (symbolic) (Kellert, 2005). Direct nature experiences include interactions with non-human-manipulated environments, such as animals, plants, forests and meadows, and activities that are self-initiated in areas with little human activity, like mountains (Kellert, 2005).

Conversely, indirect nature experiences occur in the areas that are controlled by the humans; such as botanical gardens and zoos. According to Kellert (2005), gardening is not a direct nature experience, as gardens "require human input" (p.66). The terms "direct" and “indirect" may be disputed, as they do not accurately reflect children's engagement with nature.

Vicarious experiences do not involve contact with nature, but rather experiences through “image, representation, or metaphorical expression of nature" (Kellert, 2005, p.66). Examples of vicarious or symbolic nature experiences are books, television, radio and stories. Vicarious contact with nature, according to Pergams and Zaradic (2006) is becoming more prevalent in children's lives. However, as Kellert (2005) indicates, vicarious experiences are not a phenomenon of a modern society. He argues that symbolic experiences of nature are rooted in the history of humanity and include fables, myths and totems.

Direct experiences provide the "intimacy, adventure or surprise, all of which (and much more) provide the basis for substantive development" (Kellert, 2005, p.85). The significance of direct experiences with a natural environment is further confirmed by Aaron and Witt (2011). In a semi-structured interview, Aaron and Witt (2011) questioned fifth grade minority students in Houston, Texas about the student's definition and perception about nature. In addition to an 
interview, students drew pictures of "nature" and explained their drawings to the researchers. Children with the most hands-on experiences displayed a higher awareness of nature and the natural environment, which in turn built children's connection with nature.

In another study, Wells and Lekies (2006) conducted a telephone survey with 2,004 adults living in the urban area in the United States. The study focused on the lasting effects of childhood experiences in nature and pro-environmental attitudes and behaviours in later life. The results illustrate the association between early childhood experiences and adult proenvironmental attitudes and behaviour. Activities such as hiking (wilderness experience) and gardening (domesticated experience) in childhood shaped the environmental concerns in later life, while experiences in wilderness such as hiking and camping had a greater influence than domesticated activates, like planting, on pro-environmental behaviour. These findings demonstrate the importance of direct nature experiences on building a positive relationship with nature. The limitation of these findings is that the participant's statements are their reflections on such activities retrospectively, thus the results may not be accurate. In addition, the childhood experiences were not examined from the child's perspective, which may provide a different result than those from adults. Moreover, whether these experiences are the same or different cross-culturally, has not been accounted for.

Jay and Schrami (2009) and Ozguner (2011) exposed the important role of culture on experiences in nature. In their studies, Turkish people identified using urban parks and forests for activities such as picnicking, resting and relaxing (Jay, \& Schrami, 2009; Ozguner, 2011). This is in contrast with people from Western countries who use parks and forests in a more active way, such as walking, exercising and fruit picking (Jay, \& Schrami, 2009; Ozguner, 2011). 
Similarly, the report of the California Outdoor Recreation Planning Program (California State Parks, 2005) illustrated the ethnic and racial variations of outdoor recreation patterns. The data from a telephone survey revealed that the Hispanic population preferred activities with a social component, focusing on field sports and family involvement. Likewise, activities of Dutch people in parks were related to their cultural backgrounds (Peters, Elands, \& Buijs, 2010).

Peters, Elands and Buijs (2010) used mixed method approach to examine the activities of 18 to 66 years old Dutch residents in a park. First, authors surveyed 300 first- and secondgeneration immigrants (Turkish and/or Moroccan people) and 318 native Dutch residents. Second, authors conducted 26 observations and 40 interviews additionally to the survey. However, it is unclear from the research report, how authors identified specific social groups when conducting observations. Nevertheless, results revealed that Turkish people were more likely to gather in larger groups at the park, which allowed for social activities than native Dutch residents (Peters et al., 2010).

The studies demonstrated that cultural variations exist among adults when engaging in activities in nature. Understanding the adult's preferences of natural spaces is crucial, since children depend on adults to take them there. However, cultural similarities and differences of nature experiences also need to be examined from the child's point of view, as young children experience the natural world differently (Clayton, and Myers, 2009).

\section{Barriers to Children's Exploration of Nature}

Researchers and other writers have noted that children are spending less time outdoors and more time indoors (Ghomeshi, 2013; Kellert, 2005; Louv, 2005). Comparing data collected in 1997 and 2003, Hofferth (2009) found that in a 6-year period, children aged 6 to12 in the United States spent less time in outdoor activities, and thus children's nature experiences are declining. Rosenfeld and Wise (2001) emphasize that "hyper-parenting," parental over 
involvement in their children's activities, leaves children with a limited time to engage in free play in nature. The term coined by Rosenfeld and Wise (2001) is the result of their observations of American children. Although not an empirical study, this observation is confirmed by Pain (2006) who identified children's lives being overwhelmingly controlled by adults. Children not only attend schools for most of the day, but also participate in a host of activities like organized team sports and music lessons, leaving little time to play outdoors. To exacerbate the issue, with the advancement of technology children spend more time indoors watching television, surfing the internet and playing video games (Faber Taylor, \& Kuo, 2006; Rideout, Foehr, and Roberts, 2010).

Similar trends were found in Pergams and Zaradic's (2006) study, which reported that in the United States between the years 1987 and 2003 the average persons' use of electronic media had increased. Around this time, the visitation to U.S. National Parks started to decline (Pergams, \& Zaradic, 2006). The researchers point to the relationship between electronic media and national park visitation; however, causation cannot be proven. Pergams and Zaradic (2006) argue that this phenomenon is "a manifestation of an ongoing cultural change in values" (p. 391).

Additionally, the most prevalent barrier to a nature experience is the explosion of electronic media targeted at children. In 2003, 1,065 parents with children ages 6 months to 6 years participated in a U.S. national representative telephone survey (Rideout, Vandewater, \& Wartella, 2003). Findings revealed that preschool children who watched at least two hours of television or other media a day, spent less time outdoors when compared to preschool children who watched less than two hours of television a day (Rideout et al., 2003). Although, the above findings are from the research conducted in the U.S., similar trends have been identified in 
Canada. Dr. David Suzuki, an environmental expert, described that children in Canada spend 6 hours a day engaging with electronics while only 6 minutes outside (Ghomeshi, 2013).

Another barrier to children's engagement in nature is fear. Fear is the biggest reason why parents keep their children indoors (Louv, 2005). Carver, Timperio and Crawford (2008) identify that 'stranger danger' is the most potent force causing parental anxiety for the safety of their child in the community. Clements (2004) found that $82 \%$ of American mothers limit their child's outdoor play due to perceived crime and safety concerns. In New York City, Wridt (2004) identified that local parks and playgrounds are perceived as dangerous places. Consequently, children in the study rarely played in the community parks. The fear of insect-borne diseases, ultraviolet rays and accident liability also contributes to why adults keep their children indoors (Louv, 2005). Gill (2007) blames the media for the heightened fear of the outdoors.

Children's engagement in outdoor activities has been shifting from being self-initiated to being adult-controlled (Skår, \& Krogh, 2009). Twenty Norwegian adults reflected on their childhood engagements and six of them also reflected on their 5 to 11 years-old children's experiences. This small qualitative research revealed that children's experiences with nature are more indirect. The pressure on parents to register their children in organized activities was great. The society viewed organized sports as a better and healthier choice than free nature exploration (Skår, \& Krogh, 2009). Skår and Krogh (2009) forewarned that the lack of children's selfinitiated nature experiences could lead to nature alienation. The barriers to children's exploration of nature seem to be prevalent.

\section{Summary of Literature Review}

The literature presented about the relationship between nature and children was conducted primarily in a North American context. Studies carried out in different cultural 
settings were mainly completed with older children or adults. Generally, people have positive feelings towards nature; however, attitudes towards nature were influenced by their culture. Cultural differences were also identified in peoples' experiences in natural settings; however, these variations were examined from adult perspectives.

As illustrated in the review, prior experiences shaped people's relationship with nature. Therefore, it is imperative to explore children's early encounters with nature, and the way they are the same or different in other cultures. This study looked to answer questions about children's affiliation with nature. This phenomenon was explored by understanding children's definition, emotions and engagement with nature and whether this was the same in other cultural settings. 


\section{CHAPTER 3: METHODOLOGY}

\section{Introduction}

This study focused on comparing children living in Canada to children living in Slovakia and their relationship with, and experiences in, nature. The main objective was to compare children's experiences in two different countries and examine whether these experiences and relationships with nature are culturally based. The following chapter discusses the research methods, including a description of the participants, data collection procedure, data analysis, setting, and a discussion of validity and reliability.

\section{The Social Constructivist Worldview}

The study employed a social constructivist worldview. The social constructivist worldview seeks to understand the construction of the meaning of the experiences from the participant's point of view (Creswell, 2009) in a specific context (Golafshani, 2003). The main objective of the worldview is to depend on the participants' perceptions about the studied phenomenon (Creswell, 2009). Golafshani (2003) argues that knowledge is socially constructed, so when the context changes the knowledge may also change. A child's relationship with nature is shaped over time through interaction in a particular setting (Kellert, 2005).

This research project attempted to compare Canadian and Slovakian urban children's understanding of, and relationship with nature from their perspective. It sought to understand children's experiences in the place where they live. Therefore, a draw-and-talk method, photographs of nature and a semi-structured interview with open-ended questions about nature were used to identify participant children's perspectives. This method allowed children to freely talk about their experiences and allowed the interviewer to better understand and document the children's meaning. 


\section{The Mixed Method Approach}

In this study, the mixed method approach was used to investigate children's relationships with nature. Currently, there is no consensus amongst researchers as to what constitutes a mixed method; however, researchers do agree that the method combines both qualitative and quantitative approaches (Johnson, Onwuengbuzie, \& Turner, 2007). This study employed concurrent embedded mixed method, where qualitative and quantitative data were collected simultaneously. Both open-ended and closed-ended questions were asked and children's drawings were examined in terms of their content. The primary research method was qualitative; this was further supported with quantitative analysis (Creswell, 2009). The mixed method approach is recognized as a useful method by cultural anthropologists (Jahoda, Lazarsfeld, \& Zeisel, 2009), as it serves as a measure to protect against the misinterpretation of findings (Berry et al., 2011). In addition, it strengthens the validity of the cross-cultural study as the findings were based on multiple sources (Van de Vijver, \& Chasiotis, 2010). Since the purpose of the study was to understand cultural similarities and differences from the children's perspective and support those findings statistically, the mixed approach seemed the most appropriate method in which to investigate the phenomena.

The advantage of the approach is that the researcher does not have to rely on one method to investigate the phenomena. The disadvantage is that the process is time-consuming. The researcher spends a significant amount of time collecting data and performing analysis (Creswell, 2009).

\section{The Qualitative Research Method}

The qualitative research method seeks to understand the behaviour of people in a natural setting by investigating their values, beliefs and emotions (Frankfort-Nachmias, \& Nachmias, 
2008). The purpose is to collect rich and descriptive data directly from the participant's deeper personal understanding of the phenomena or experience. A qualitative method looks to understand, rather than to quantify or generalize findings (Golafshani, 2003). This approach allowed for a deeper understanding of children's feelings and perceptions that, according to Britten (2011), are difficult to measure by using other methods. Exploring the relationships children have with nature, allows a qualitative researcher the ability to capture children's perspectives and lived experiences.

In the research community, qualitative research has been accepted as an appropriate method to conduct a study with children (Fargas-Malet, McSherry, Larkin, \& Robinson, 2010; Mitchell, Theron, Stuart, Smith, \& Campbell, 2011b). Creswell (2009) indicates that anyone engaged in qualitative research methods supports "a way of looking at research that honors an inductive style, a focus on individual meaning, and the importance of rendering the complexity of a situation" (p.4). In qualitative research, researchers usually employ multiple sources of data collection (Creswell, 2009). The collection of multiple data sources increases the validity of the study.

In this study, the draw-and-talk method (Mitchell, Theron, Smith, \& Stuart, 2011a), photographs (Shepardson, 2005) and a semi-structured interview with open-ended questions (Strife, 2008) were deemed as appropriate, since they allowed children to communicate what they thought.

\section{The Grounded Theory Research Strategy}

The grounded theory is a unique kind of qualitative research where the researcher constructs a theory that is grounded in the participants' perspective (Creswell, 2009). The purpose of the grounded theory is to expand current theories by including people's everyday 
experiences (Collingridge, \& Gantt, 2008). This approach involves in depth interviews with participants who have familiarity with the phenomenon. Researchers continuously gather more data and create categories that are based on the continuous comparison of the collected data (Creswell, 2009).

This study compared the relationship and experiences children have with nature in two different countries. The purpose of the study was to compare similarities and differences of participant children's experiences from their perspective. Multiple open-ended questions were asked to gain a deeper understanding of the participant children's relationship with nature.

\section{The Quantitative Research Method}

The quantitative method seeks to examine the relationship between variables while representing the findings numerically (Creswell, 2009). Researchers who employ this approach test a theory deductively, that is, confirming or refuting hypotheses (Creswell, 2009). The aim is to replicate and generalize the findings (Creswell, 2009).

The quantitative approach was a secondary method used in investigating children's relationships with nature. The research hypothesis was answered first and then additional questions arose during the analysis process. The quantitative approach illustrated similarities and differences statistically. Data collected in the draw-and-talk method were used to support or refute the hypothesis. Children's drawings were examined by content analysis. Many researchers working with children employed the quantitative method (e.g., Boeve-De Pauw, \& Van Petegem, 2012; Cheng, \& Monroe, 2012); therefore, this approach was deemed appropriate.

\section{Participants}

A total of 52 children were included in the study. In order to get meaningful results while conducting a comparison study, the samples from each country were equal in size. Twenty-six 
children were from Toronto, Canada, and 26 children were from Bratislava, Slovakia. Fifty-two participants is a large enough sample to collect meaningful data for fundamental quantitative and qualitative analyses.

The participants for this study included children aged 5 to 8 years old. According to Kellert (1996), children in this age range are more receptive to changes in values in regard to nature. Children who are in this age group have a considerable knowledge about nature (Duschl, Schweingruber, \& Shouse, 2007). Younger children were excluded as they have more difficulty reasoning (Duschl et al., 2007) and older children were excluded as early childhood in Canada is considered only up to eight years-old.

To enable a variety of children's perspectives, the study was comprised of children of both genders, an age range of 4 years (5 to 8), and a combination of school and kindergarten centre settings. The sample in Toronto, Canada included children aged $5(n=11), 6(n=6), 7(n=7)$ and $8(n=2)$; with a mean age of 6.0 years old. The sample in Bratislava, Slovakia included children aged $5(n=1), 6(n=11), 7(n=13)$ and $8(n=1)$; with a mean age of 6.5 years. One seven-year-old girl from Slovakia was dropped from the research. The child was born in Slovakia; however, neither Slovak nor English was her first language. The language barrier prevented the child from contributing to the dialogue and queries about her drawings. Another child of the same age was recruited and included as a substitute participant in the study to maintain an equal number of participants in each setting.

A total of 8 boys and 18 girls from Toronto and 13 boys and 13 girls from Bratislava were included in this study. The main purpose of the study was to compare children from Canada to children from Slovakia and their conception of nature. In order to conduct a meaningful comparative study, children must have been born and living in the country they were 
representing - Canada, if representing the Canadian population and Slovakia, if representing the Slovak population.

\section{Sampling Method}

In order to follow the objectives of the study, a purposive sampling method was used. The purposive sampling served to select participants and settings that "best help the researcher to understand the problem and the research question" (Creswell, 2009, p.178). The number of participants was predetermined in order to keep the project manageable and to facilitate conducting the study within a given period. In both Canadian and Slovak settings, the children showed a high level of interest in participating in the study. In each setting children were randomly selected from the children who gave consent.

\section{Recruitment of Participants}

This study focused on children living in urban settings in two different countries. I chose to explore children in an urban setting, as increasingly more children are growing up in cities. Children from Toronto, Canada were selected for several reasons. Toronto has the highest population in Canada (Statistics Canada, 2012). Currently there is an intensification of condominium development in the area. Lastly, Toronto was chosen for practical reasons. It was conveniently located to my place of residence.

Children from Bratislava, Slovakia were selected to mirror Toronto’s largest urban setting in Canada. Bratislava is the largest city in Slovakia (Statistical Office, 2009). Fewer studies focus on children from Eastern Europe. Research in Slovakia provides an opportunity to expand upon the limited number of studies conducted in the region. Lastly, Bratislava was selected as it is a place where I was born and raised and, thus, I understand the culture and the language. 
All research sites were contacted after approval from the Ryerson University Research Ethics Board. The research sites were selected based on their permission and willingness to participate. Children in the Canadian setting were recruited from two independent schools and one kindergarten centre. In the kindergarten centre a personal contact assisted in introducing the research site; however, participation was voluntary. In the Slovak setting, children were recruited from one public school and one kindergarten centre.

Initially, principals or directors of the schools/ kindergartens were contacted in order to explain the project and ask for their permission. After the directors' permission, and teachers' willingness to conduct a study in their classroom, teachers distributed to and collected consent forms from families. This approach was based on the schools' preferences. The teachers were provided with a detailed description of the recruitment procedure.

In the Slovak setting, all communication was conducted through e-mails. A personal contact, who was given detail instructions, assisted in delivering the Recruitment Letter (see Appendix A) and Consent Agreement documents (see Appendix B) to the schools' principals. Children, whose parents provided consent for their children to participate in the study were asked for their written assent (see Appendix C).

Finally, all children who participated in the research study received a package of colored pencils as a token of my appreciation for their time. The recruitment letter did not state that children would be receiving a gift; however, due to ethical considerations, the consent agreement did.

\section{Setting}

The study was conducted at the participant children's schools/childcare centres. The reason for using these settings was to provide a neutral, non-threatening environment for the 
children. The environments were well known by children, thus, a more comfortable setting for them (Langston, Abbott, Lewis, \& Kellett, 2004). The locations were also convenient to families, as their privacy was not disturbed and they did not need to make special meeting arrangements. The exact time and place of the research was established with the schools' directors/principals. The individual face-to-face interviews took place during school hours between $8 \mathrm{am}$ to 4:30pm. Children were interviewed in one of the following areas: classroom, school library, quiet area in the school hallway or the teachers' lounge in order to provide them with a private space.

\section{Challenges in Recruitment}

During the participant recruitment, I was faced with several challenges, which resulted in focusing on a cultural comparison only. The initial recruitment challenge occurred while attempting to gain approval with the Toronto Catholic District School Board (TCDSB). A specific TCDSB school principal was interested in the study, but the TCDSB ethics board did not grant permission to collect data at any TCDSB school.

Another challenge occurred when interested participants in the two target study countries did not have equally matched ages and genders of children. Due to the limited time constraints on the study, the priority was to maintain a cultural comparison, thus equal distributions of age and gender were not maintained.

\section{Pilot Study}

During my course "Social Research with Children," I conducted a pilot study to test my proposed research. I wanted to examine whether children who are 4 and 5 years old are familiar with the term "nature," if drawings and photographs of nature were appropriate methods to investigate this phenomenon and the time needed for interviews. Some adjustments were made with regard to the order of the research instruments. In the pilot study, children were shown 
photographs of nature first, then they were asked to draw picture. This process was reversed, as the two children participating in the study were able and willing to talk about nature. Reversing the order prevented children being influenced by photographs.

\section{Data Collection Process and Tools}

Children participating in the study were engaged in individual face-to-face interviews. Some children may have been uncomfortable speaking in a group, thus individual interviews were deemed as a preferred method (Hennessy, \& Heary, 2005). Roulston (2011) states that individual interviews are especially beneficial for participants who are introverted or reserved when speaking in front of others. Additionally, I wanted to ensure that the answers of other participants would not influence the children's answers. Hennessy and Heary (2005) state that the drawback of group interviews is the collective influencing other participants. During the individual interviews, children may have felt intimidated by the researcher (Einarsdóttir, 2007).

Before the interview, I established rapport by asking unthreatening questions (Cameron, 2005), such as, about their day. Furthermore, participants were informed that there were no right or wrong answers, that their name and the name of the schools would not be used and that their ability to draw was not being assessed.

The data collection in Canada took place in May 2013 and in Slovakia in June 2013. The individual interviews lasted between 25 minutes and 55 minutes in length. The differences in interview durations were function of how long children took to draw their pictures and how talkative they were during the interview. Some children preferred to talk while drawing, whereas others preferred to draw quietly and talk about their drawing afterwards.

Since the "new sociology of childhood" views children as competent individuals able to express their perceptions, the selected data collection tools had to be flexible. Therefore, multiple 
methods of data collection were employed. This in turn, also served as a triangulation. Triangulation is wide-spread among researchers in social sciences (Mitchell et al., 2011b). As noted by Patton (2002), employing multiple sources of data collection strengthens the study. The benefit of triangulation is that it increases objectivity of the researched phenomena and overcomes the limitations posed by a single method (Frankfort-Nachmias, \& Nachmias, 2008). In keeping with the objective of this study, the nature drawing activity, the use of photographs of nature and the semi-structured interview about nature allowed children to freely express their experiences and feelings about nature.

To better understand whether children were familiar with the term "nature," they were preliminarily asked, "Do you know what nature is?" After the initial question, children participated in a drawing activity. Immediately after, children were invited to partake in a semistructured interview. Lastly, children were shown four photographs of nature and asked about their experiences in similar settings. The detail description of the data collection tools is described below. The basic demographic data - age, and gender - were collected in a consent agreement.

\section{Exploratory Questions}

The concept of nature can be a challenging term to define. In order to conduct the study, I needed to make sure that children were familiar with the term. Therefore, three opening questions were asked, "Do you know what nature is?", "What is nature?" and "Where do you see nature?" (see Appendix D). According to Irwin and Johnson (2005) when examining a specific concept or term, it is imperative to start with a closed-ended question. This approach provided the initial direction the study interview needed to take and allowed for establishing rapport with a child. As previously discussed, children who were familiar with the term first drew a picture, 
then participated in the semi-structured interview and lastly participated in a dialogue about photographs of nature. If children were not familiar with the term, photographs of nature were shown first and then children drew a picture and ended with the semi-structured interview. See the section Photographs on page 34 for more details.

\section{Children's Drawings}

Drawings done by the children served as a tool to explore the children's definition of nature and the activities children do in nature. The primary advantage of using drawings is they are perceived as easy (Mitchell et al., 2011a), and fun for children (Veale, 2005) while allowing for non-verbal expression (Docket, \& Perry, 2005) and "time to think" (Punch, 2002, p.331). Moreover, Mitchell, Theron, Smith, and Stuart (2011a) argue that drawings serve as an icebreaker. In the research community, many researchers employed the drawing method to engage children in research projects (Dockett, \& Perry, 2005; Kalvaitis, \& Monhard, 2012; Strife, 2008). However, children must be familiar with how to draw in order to get meaningful results (Veale, 2005). Moreover, the choice of drawing tools must be culturally relevant and age appropriate (Mitchell et al., 2011b). Therefore, a variety of drawing materials, such as crayons, markers, pencils and white paper were provided. During the initial meeting with school directors/principals, I made sure that children were familiar with the drawing medium.

A shortcoming of just employing drawing as the method for data collection is that subsequent interpretation may not reflect what the author meant or intended (Dockett, \& Perry, 2005). Therefore, children were provided with the option to talk about their drawing. The drawand-tell method was employed in order to increase the credibility of the study and avoid researchers' misinterpretation of the drawing (Mitchell et al., 2011b). 
Children were asked: "Draw a picture of nature and yourself doing something in nature" (see Appendix E). The time children took to draw nature varied between 10 and 30 minutes. While children were drawing, I sat quietly and observed. Children were provided with the option to talk while drawing; however, some children preferred talking about their drawings after. Both approaches allowed the children to clarify what they drew, thus maximizing the validity of the data.

\section{Semi-Structured Interviews}

Mitchell, Theron, Stuart, Smith, \& Campbell (2011b) remind researchers that drawing is created in a specific time and environment, thus verbal explanation is needed. Therefore, the first part of the semi-structured interview served to clarify what individual children drew to assure the correct interpretation of their drawing. The second part of the semi-structured interview asked open-ended questions about nature and children's experiences in nature, where children could

freely elaborate about the individual questions (see Appendix F). For example, I asked, "What do you do in nature?" and "Why?" "How do you feel when you are in a nature?" and "Why?"

The advantage of the interview is that it allows for probing. Probing can "motivate the respondent to elaborate or clarify an answer or to explain the reasons behind the answer..." (Frankfort-Nachmias, \& Nachmias, 2008, p.221). The weakness of the interview is that a researcher's presence may bias children's responses (Creswell, 2009). Moreover, an interview cannot assure anonymity and the participant may feel intimidated (Frankfort-Nachmias, \& Nachmias, 2008, p.221). Therefore, children were informed that there are no right or wrong answers and their names would not be used. 


\section{Photographs}

The reason to have and use photographs of nature was the assumption that not all children may have been familiar with the term "nature" or might have difficulty expressing themselves. The photographs served to elicit a conversation about nature by exploring the content of the photographs, what children do in places similar to the images and what their feelings about the settings are (see Appendix G). Another reason for using photographs as a data collection tool was to expand on the children's experiences in a particular setting. During the drawing activity, children focused primarily on one type of a setting in nature and excluded other experiences in nature. Presenting photographs of varied contexts allowed children to talk about other experiences in nature in addition to what they drew. Lastly, the images served as a talking tool, where children did not have to have direct eye contact with the researcher (Dockett, \& Perry, 2005). This approach was beneficial for the children who were more reserved or timid.

Children were shown four photographs of nature that were pre-selected by the researcher (see Appendix H). Only four images were used in order not to overly distract the focus and minimize boredom of the children. The photographs were selected to represent the different context and elements of nature based on my definition of what nature is. The images were shown in a particular order, from the most likely to the least likely to be in the selected cities. The most probable was a representation of grass and fields and least probable was a depiction of mountains, as no mountains are in the selected cities. The image of a forest and a photograph of a beach/water were equally likely to be found in the cities. Both locations have forest or ravines and lakes in the cities. 


\section{Data Recording Procedures}

The individual interviews followed an interview protocol. The protocol included a participant's number that was assigned by the researcher, the date, time, interview location, questions and subsidiary questions asked with regard to nature. Where given parental consent and child's assent, interviews were voice recorded in order to accurately capture all the answers. Notes were also taken in addition to voice recording. In the event that parents or children did not give assent to a voice recording, only written notes were taken. All 52 interviews were transcribed using a computer.

\section{Data Organization}

All data collected, drawings and interviews, were organized by the location, Canada and Slovakia, and by participants within each location. Consent and assent forms were kept separately from the data in order to de-identify the participants. All data were saved on a flash drive and a $\mathrm{CD}$, and were stored in a safe.

\section{The Data Analysis Procedure}

Data were collected to compare the perception and experiences children have in nature, in two different countries. Qualitative and quantitative data analyses were conducted separately and used to address the research questions and hypotheses related to definitions of nature, activities in nature, children's feelings towards nature, types of direct experiences and types of natural elements in children's drawings. The quantitative findings provided measurable evidence, while qualitative results illustrated children's experiences and meaning (Check, \& Schutt, 2012). Many researchers working with children employ both quantitative and qualitative data analysis (e.g., Aaron, \& Witt, 2011; Strife, 2008). 
To compare the two cultures, the qualitative and quantitative data gathered at each location were analyzed separately. Coding was developed to distinguish children from Toronto and Bratislava. Numbers were assigned to children to maintain confidentiality. Within the main categories, which were framed by the research questions and hypotheses, data were separated based on the children's location. Translation of the data from Slovak to English language occurred as needed.

\section{The Qualitative Data Analysis Procedure}

According to Creswell (2009), data gathering and analysis occurs simultaneously, involving the collection of open-ended data. In qualitative data analysis, the focus is on the meaning and, thus, themes must emerge from the data (Check, \& Schutt, 2012). In this study, the qualitative data were analyzed by qualitative software QSR NVivo (Version 10). This software helped with the organization and analysis of the large amount of qualitative data.

The data analysis procedure used a grounded theory that employed several steps (Collingridge, \& Gantt, 2008). The first step involved the organization of the data, which included transcribing the interviews and field notes (Creswell, 2009). Once transcribed, all data, including images, were imported into NVivo. The next step consisted of creating an open code to identify general themes. Open codes were continuously compared to identify similarities and differences of the responses (Collingridge, \& Gantt, 2008). The codes were centered on the research questions. Once the broad categories were established, subcategories were created. When the codes and subcategories were completed, the themes from both settings were compared. This process allowed for examination of similarities and differences between the children living in Toronto and Bratislava. 


\section{Quantitative Data Analysis Procedure}

The objective of the quantitative data analysis was to test the relationship between variables and quantify the results (Golafshani, 2003). Content analysis of the children's drawings allowed for a numerical representation of the similarities and differences between the cultures. The data were analyzed using SPSS (Version 20).

In the first hypothesis, it was proposed: "There will be differences between children from Canada and Slovakia regarding the number of children drawing direct experiences with nature." Data gathered during the drawing activity were corroborated during the semi-structured interviews with the children. The Chi-square Goodness of Fit test was used to compare Canadian and Slovakian children's drawings of direct experiences with nature.

The independent variable was whether the participants were from Canada or Slovakia. The dependent variable was the number of children with direct experiences with nature in their drawings. The aim was to examine whether more Canadian or more Slovakian children depict having direct nature experiences. For detailed examples of direct experiences, see Table I1.

The second hypothesis: "There will be differences in the number of identifiable types of natural elements in the Canadian and Slovakian children's drawings" was analyzed by using the SPSS two-tailed T-test. In the drawings, each drawn element was accounted for and placed into a category. To prevent a misinterpretation of the child's drawing, the answers from the first part of the interview further served to clarify the meaning of the drawing (Mitchell et al., 2011b). The independent variable was whether the participant was from Canada or Slovakia. The dependent variable was the number of types of natural elements in the pictures. Natural elements included different types of trees, berries, bushes, grass, rocks, snow, dirt, woodchip, water, wind, sky, rain, clouds, mountains, rainbow and animals. 
Each different type of element counted as one. For example, an animal, bush and tree represented in a drawing constituted a count of three. Different types of trees, such as a leaf tree and a fruit tree counted as two as they were two different types of trees. Whereas, when children drew three pine trees, it only counted as one, as children drew only a one type of a tree. The reason for counting the different types of natural elements and not the number of all natural elements in the drawings was to examine the children's understanding of nature. It was believed that the greater variety of nature elements found in a child's drawing implies that that child has a deeper awareness of the diversity of nature.

\section{Validity, Reliability and Qualitative Rigour}

The analysis included careful reading and re-reading of the data to gain a general understanding of the collected information (Creswell, 2009). In order to enhance the credibility of the study, the research supervisor was consulted during the coding process. In addition, peerdebriefing involving a person not part of the study helped contribute to the credibility of the study (Creswell, 2009). As mentioned in the Data Collection Process and Tools, to increase the validity of the study, a triangulation method was employed by using the drawing activity, photographs of nature and a semi-structured interview. The semi-structured interview also served as an opportunity for the children to clarify their drawings. Moreover, children's responses were clarified by checking back with them.

A potential threat to internal validity is validity of self-report data, where children could withhold their honest thoughts. Another threat to the internal validity is sampling, where the participants selected who volunteered could be predisposed to have a positive relationship with nature. 


\section{Chapter 4: RESULTS}

The purpose of this section is to present the research findings. The results are organized by research topics. Research topics include the definition of nature, children's experiences in nature, their feelings about nature, children's illustrated direct experiences with nature and natural elements within their drawings. The findings were further divided by location. This approach allowed for a direct comparison of children's responses across two cultures within the central questions. All names used are pseudonyms in order to maintain confidentiality. As a note, sections marked with '*' are not direct quotes, as families did not provide consent to voice record their child.

\section{Definition of Nature}

The children's definitions of nature were in response to the question "What is nature?" and were further explored by the children's drawings of nature. In total, 51 out of 52 children defined nature as living things. Living things consisted of grass, plants, trees, bugs or animals. Several children also included natural non-living elements such as air, rocks and snow, as well as man-made structures, such as schools, cars and buildings. In addition to living and non-living elements, only a few children stated that humans have a place in nature. Children referred to humans as "friends" and "people" (see Table 2).

Children in both cultures defined nature as being outside. When considering children's drawings, all children (100\%) drew the outdoors. As well, when asked, "Where do you see nature?" twenty-two Canadian children (85\%) and 25 Slovakian children (95\%) said nature is outside. Some differences were noted in regard to nature being outside. Canadian children talked about nature being an outdoor space, while Slovak children talked about nature as being specific places, such as a forest and a desert (see Table 2). In addition to nature being outside, the same 
number of children in Canada $(n=8)$ as well as Slovakia $(n=8)$ said nature was inside. Children from both cultures identified plants and flowers that are inside as being nature when asked, "Do you see nature inside?"

\section{Additional Findings about Children's Definition of Nature}

A non-statistically significant difference observed between the Slovakian children and the Canadian was that Canadian children talked about a greater variety of non-living elements than the Slovak children did. In total, Canadian children included 11 different types of non-living items on average, while Slovak children included only six items (see Table I3).

The children's definition of nature was also examined in terms of where people fit in. Children responded to the question "Are people part of the nature? Why?" In total, 38 out of 52 children $(73 \%)$ indicated that humans are part of nature. Specifically, 19 Canadian $(73 \%)$ and 19 Slovakian children $(73 \%)$ believed that humans have a place in nature. The majority of children perceived people as nature because people live and people are physically present in nature. These justifications were the same cross-culturally. On the other hand, a few children commented that humans were not part of nature. Several children did not elaborate, with the exception of the Slovakian children who reasoned: "Because, birds, hedgehogs, mice, birds live there; and people don't live there" (Monika, 7), "because we are not plants" (Helena, 6) and "they are people, people are destroying nature; they don't care" (Tibor, 7)*.

Interestingly, out of 52 children, only one child described nature in terms of having restorative qualities. Nature was described by this child, as a place to calm down. The following passages are excerpts from the discussion during the interview with a seven-year-old from Canada:

Researcher: What do you usually do in nature? 
Julie: I usually like just walk and look at it, then sometimes, I just feel calm and I just sit down and think sometimes.

Researcher: How do you like that?

Julie: I really like it because it's a place to be quiet and where you can like have no noise, you can just listen to nature. It's almost like nature is speaking to you.

Later during the interview:

Researcher: Do you go enough to nature or would you like to spend more time in nature? Julie: I would like to spend more time in nature because I don't always, I'm not usually around the forest or like rainforest, so I like to go to nature more.

Researcher: Why would you like to go there more?

Julie: Cause, it's just, it calms me down like, when I'm like really tense, I'm like mad at something, I can go there and just calm down.

The last finding is the number of young children understanding the term "nature."

Children responded to the questions "What is nature?" "Where do you see nature?" as well as to,

"Draw a picture of nature and yourself doing something in nature." In total, 51 out of 52 children were able to articulate what nature means to them. Only one child from Canada did not provide a verbal definition of nature; however, the child's picture was a depiction of outdoors.

Table 2

Children's Definition of Nature

\begin{tabular}{|c|c|c|}
\hline Definition & $\begin{array}{c}\text { Canada } \\
\text { Representative Quote }\end{array}$ & $\begin{array}{c}\text { Slovakia } \\
\text { Representative Quote }\end{array}$ \\
\hline \multirow[t]{2}{*}{$\begin{array}{l}\text { Living } \\
\text { Things }\end{array}$} & $\begin{array}{l}\text { Trees, and leafs, acorn, bears, and } \\
\text { lions... tiger... plants (Adam, 5). }\end{array}$ & $\begin{array}{l}\text { Nature is, that animals live there and } \\
\text { there are living things (Nikolka, } 7) \text {. }\end{array}$ \\
\hline & $\begin{array}{l}\text { Leaves, snow, grass, twigs, rocks, } \\
\text { pebbles, sand, water, flowers, tulips, } \\
\text { seeds (Gabi, 5). }\end{array}$ & $\begin{array}{l}\text { It is, flowers, birds, bugs, trees, } \\
\text { ladybugs, and simply, grass } \\
\text { (Monika,7). }\end{array}$ \\
\hline $\begin{array}{l}\text { Natural Non- } \\
\text { Living } \\
\text { Things }\end{array}$ & $\begin{array}{l}\text { It's like trees, flowers, leaves, grass, } \\
\text { and dirt, soil, water, school, houses } \\
\text { (Sally, 7). }\end{array}$ & $\begin{array}{l}\text { Trees, animals, fresh air, flowers (Jana, } \\
6 \text { ). }\end{array}$ \\
\hline
\end{tabular}




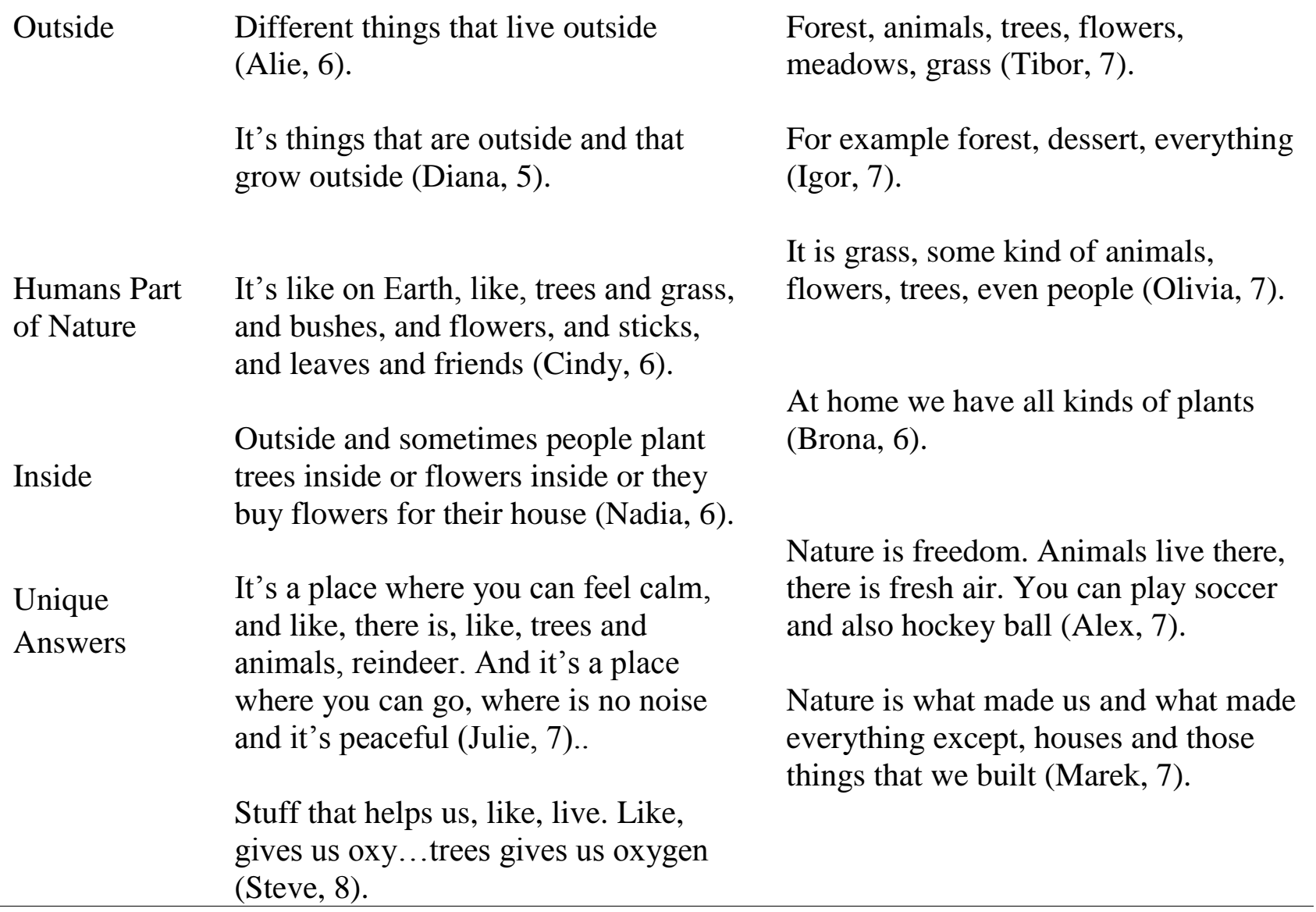

\section{Experiences in Nature}

To better understand children's relationships with nature, children's experiences were examined through their drawings, photographs of nature, and semi-structured interviews. The primary purpose was to examine whether children have direct experiences with nature and if so, what these experiences were. Children's answers were prompted by the question "What do you do in nature (or in the place like on the photograph)?" and "Draw a picture of nature and yourself doing something in nature."

Children from Canada and Slovakia have direct experiences in nature. Although, children engaged in many similar activities, such as building with snow, exploring nature, gardening, and walking, some variations in their experiences with nature have been observed. A Chi-Square Goodness of Fit test analysis revealed that 12 children from Slovakia (46\%) and two Canadian 
children $(8 \%)$ pick food in nature. These findings were statistically significant $(p=.008$, twotailed, $d f=1$ ) (see Table I4) and are presented in Figure 5. Furthermore, children in Slovakia mentioned gathering more different types of foods, such as apples, cherries, mushrooms, berries, rosa canina, elderberry and fish, while children in Canada talked about picking apples, raspberries and catching fish.

\section{Figure 5}

\section{Eating in Nature}

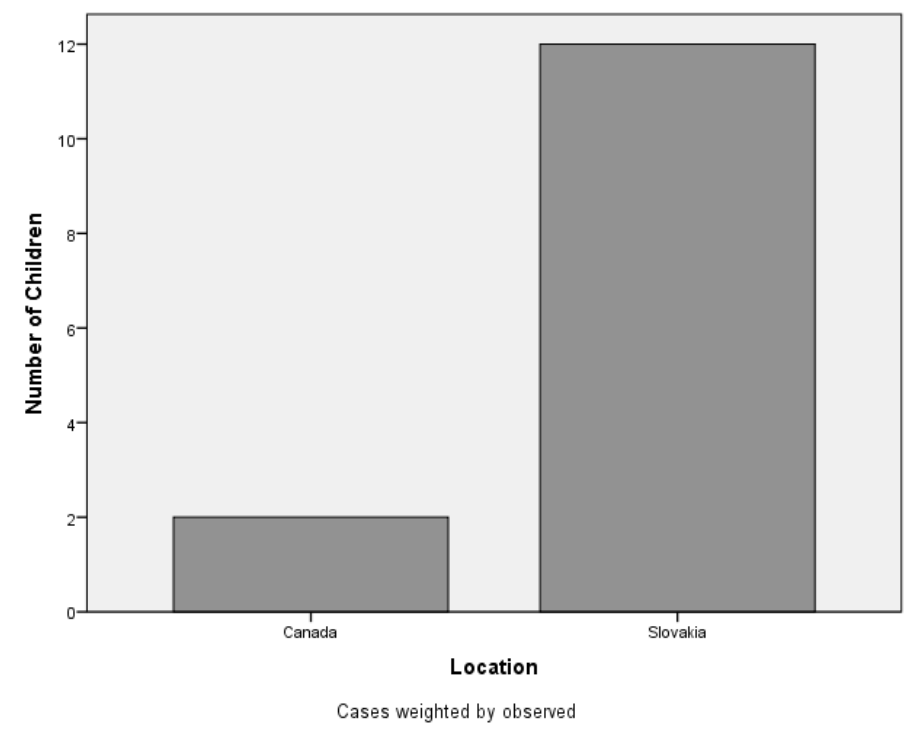

Figure 5. Number of children eating in nature.

Children from both cultures talked about their eating experiences in nature. Five Canadian children (19\%) mentioned or drew eating in nature while ten Slovakian children (38\%) did. Qualitative differences between the Canadian and the Slovak children's responses concerning eating experiences in nature were identified. However, statistically, using the Chisquare Goodness of Fit test, these findings were not significant ( $p=.197$, two-tailed, $d f=1)$ (see Table I5). Canadian children talked about having a picnic or celebrating a birthday in nature, 
Slovak children spoke about making a campfire and roasting their food. The only time Canadian children discussed making a campfire was when they went camping. The differences in the children's eating experiences in nature are illustrated in Figures 6 and 7.

Figure 6

Eating in Nature

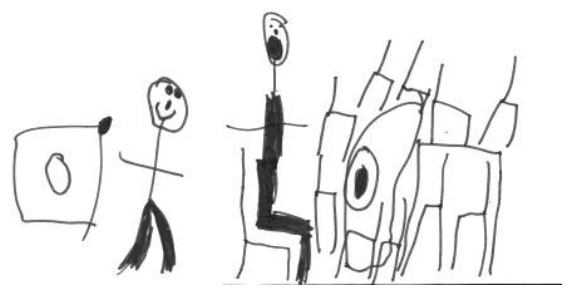

Figure 6. Ronnie, 5, Canada. Celebrating birthday.
Figure 7

Eating in Nature

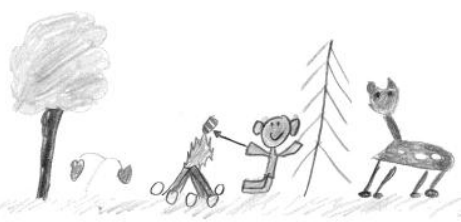

Figure 7. Tibor, 7, Slovakia. Cook out.

In total, 16 children talked about gardening. Ten Canadian children (38\%) talked about raking leaves, watering plants or weeding compared to six Slovakian children (23\%) who talked about mowing grass, pruning trees, watering plants or turning compost. More specifically, the ten children in Canada were girls, while four of the six children from Slovakia were boys.

An important element of the children's experiences in nature was that they learned while in nature. Qualitative variations between Canadian and Slovakian children in how they learned were identified. Children in both cultures talked about building and examining nature. A 7-yearold Canadian girl discussed using technology in nature. This was an indirect nature experience as the technology recognized and identified different species of plants and trees. In contrast, a fiveyear old boy from Slovakia engaged in a direct learning experience by identifying animal footprints using printed images as a guide. 


\section{Canada}

I look at leafs, I use a "leaf snap." I can take pictures of the leaf in the backyard (Natalia, 7).*

\section{Slovakia}

Michal: I already found, saw already, because, I already saw wolf's footprints.

Researcher: Where did you see it?

Michal: In the forest, at the edge of the forest they were.

Researcher: How did you know those were the wolf's footprints?

Michal: Because I know the footprints from that paper.

Researcher: You have some kind of a paper with footprints?

Michal: Daddy printed it out for me, because there are all kinds of footprints.

Finally, the last mentioned experience children had in nature was their involvement in quiet activities. Quiet activities were based on the children's comments describing reading a book, laying on the grass or sand, tanning, solving puzzles, thinking, or just resting. In total, 23 children cross-culturally talked about the quiet activities they do in nature; more specifically, seven Canadian children (27\%) and 16 Slovakian children (62\%). Differences were not found in the type of quiet activities, as children from both settings mentioned similar experiences. One stark contrast between the children's experiences was that nine children from Slovakia (35\%) mentioned tanning while only one Canadian child (4\%) discussed tanning. Utilizing the Chisquare Goodness of Fit test, these findings are significant $(p=.011$, two-tailed, $d f=1)$ (see Table I6). The following are some examples of children's quiet activities in nature.

\section{Canada}

I, like, think about stuff (Mary, 7).

Researcher: Have you been where is grass?

Angela: I like to lay on it and watch the clouds.

\section{Slovakia}

Researcher: What do you do on grass?

Petra: Sometimes I lay down in it when it's warm. 
Researcher: What do you do on the beach?

Robko: I also suntan.

\section{Children's Feelings towards Nature}

To better understand how children feel in nature, they were asked to express their feelings and to provide reasoning for their emotions. Children's feelings were examined during the semi-structured interviews and discussions over the photographs of nature. Children were asked, "How do you feel in nature?" Both, positive and negative feelings were identified.

Commonalities across cultures emerged as all 52 children (100\%) identified feeling good/happy. In addition to feeling good/happy, some children talked about feeling relaxed and free. A few children in both cultural settings, identified feeling scared in nature. The fear of animals was the most common reason identified for having these feelings. Some children in Canada also included being scared of nature for its characteristics (e.g., height, darkness). Even though all 52 children acknowledged feeling good/happy in nature, one Canadian girl also said she was bored in nature. See Table 7 for examples of children's quotes about children's feelings about nature.

Table 7

Children's Feelings in Nature

\begin{tabular}{lll}
\hline Themes & \multicolumn{1}{c}{ Canada } & \multicolumn{1}{c}{ Slovakia } \\
\hline $\begin{array}{l}\text { Happy/ } \\
\text { Good }\end{array}$ & $\begin{array}{l}\text { Uhm, great. Because there is lots of } \\
\text { things to see. Like, like, uhm like } \\
\text { nests (Kiki, 5) }\end{array}$ & $\begin{array}{l}\text { Good. Because is fresh air and } \\
\text { sometimes we can see a doe or a deer } \\
\text { and that's it (Helenka, 6) }\end{array}$ \\
& $\begin{array}{l}\text { So happy! Because there are lots of } \\
\text { trees (Ronnie, 5) }\end{array}$ & $\begin{array}{l}\text { Good. Because there is fresh air } \\
\text { (Igor, 7) }\end{array}$ \\
Relaxed & $\begin{array}{l}\text { Calm, relaxed. Cause nature is one of } \\
\text { those things that like people love, } \\
\text { like people wanna be around because } \\
\text { it's so quiet and calm (Julie,7) }\end{array}$ & Outside is relaxing (Katka, 7)
\end{tabular}


Free Feels good because being outside. Because you can do all kinds of Being outside is being free, do things (Monika, 7). whatever I want (Victoria, 7)*

Scared Scared. It's because there are some really wild animals and sometimes the wolfs are kind of scary. And sometimes you hear wild animals that you think they're coming for you (Katy, 20)

I never been on a mountain. Cause, mountains are way high, so I'm little scared (Gabi, 5)

The sea is sometimes deep, so I am sometimes afraid to go into the water because there are crabs, but when I am in deep water, I know that there, that I can't just like that step on the bottom, so I'm not scared (Alex, 7 )

Don't want to meet wolf; can eat me and wild pig is dangerous, viper is poisonous - I am afraid of snakes, they would do bad things to me, they attack people. (Tibor,7)

Bored I feel happy. I also feel bored because bored is kind of... I like to do stuff so I'm kind of bored sometimes, there is not something very fun to do (Laurie, 6).

As highlighted above, children have a variety of feelings in nature. To further explore children's positive feelings, they were asked "What do you like about nature?" While the children provided a variety of responses, only a few will be discussed in this section. A significant number of children in both cultural settings expressed liking nature for its attributes. They positively identified with the smells, sounds, and the aesthetics of nature. There were no differences across the cultures.

\section{Canada}

I like that there is like open spaces and tight in spaces and just like changes like there is flowers and like trees so I can climb, I like how they smell and I can play with, and dandelions I can make head bands with (Julie, 7).

Birds make noise - it's nice (Tim, 5)*

Calm in the forest (Natalia, 7) 


\section{Slovakia}

I like in the forest that there are trees and animals (Nikolka, 7)

I like nature because of cheerful colours. Rainbow has cheerful colours (Ella, 6)*

That there is grass, you have peace and that it is pretty (Riki, 7)

A few Canadian children expressed liking nature because they feel free. Similarly, a few children from Slovakia communicated liking the freedom they have in nature.

\section{Canada}

I like that you feel free, it's fun, you can do whatever you want, like climb trees, do fun stuff (Mary, 7)

\section{Slovakia}

Researcher: What do you do in winter?

Riki: Mostly we have snowball fight and we go skiing.

Researcher: Do you like skiing?

Riki: Like, but I don't like, when somebody bosses around what should you ski.

Since all children identified positive feelings in nature, children were queried about their negative feelings in order to get a wider range of perspectives. To delve deeper into the children's emotions they were asked, "What do you dislike about nature?" Children in both cultural settings talked about not liking bugs and plants that hurt or annoy them. Children in both cultural settings did not like when nature influences what they could do in nature.

\section{Canada}

Kiki: That, there are bumblebees.

Researcher: You don't like bumblebees?

Kiki: No

Researcher: Why don't you like bumblebees?

Kiki: Cause they sting you

Dislike waves because wash away castles and holes (Sally, 7) 


\section{Slovakia}

Mosquitoes and flies. Because they perpetually fly around your head (Igor, 7)

In the meadow I don't like when, there, sometimes rains. Because, then I can't enjoy it (Riki, 7)

A cultural variation in the children's responses was noted when only Canadian children talked about not liking nature because nature does not have 'fun stuff.' Moreover, Canadian children expressed not liking to touch bugs.

\section{Canada}

Laurie: I don't quite like nature because it doesn't have always fun stuff.

Researcher: What makes it fun stuff?

Laurie: Swings, toys.

I don't like to touch the worms ... because they go underground (Oliver, 5)

Further cultural differences were noted when only Slovak children conveyed pollution as being a major aspect of what children dislike about nature.

\section{Slovakia}

Zuzka: For example, when there is garbage.

Researcher: Why?

Zuzka: Because it looks bad.

Otto: That we couldn't drink from the stream

Researcher: Why?

Otto: Because, mom was saying that there is a lot of germs.

\section{Additional Findings about Children's Feelings}

In order to understand the children's feelings towards nature, it is necessary to explore the cause of these feelings. Three major themes emerged from the interviews. Children's feelings were influenced by nature's characteristics (e.g., being beautiful, smelling good), or by the activities children did in nature (playing, running, exploring) or both nature's attributes and activities in nature. However, in this paper, the findings will concentrate only on the first two 
categories, as the third category is a combination of the other two. Even though all 52 children identified their emotions, only 50 children provided an explanation for their feelings. In total, 24 (96\%) Canadian children, and 26 (100\%) Slovak children provided justification for their feelings. Employing the Chi-square Goodness of Fit test, the findings were not statistically significant ( $p=.335$, two-tailed, $d f=1$ ) (see Table I8). Twelve Slovak children (46\%) and seven Canadian children (33\%) characterized their feelings being influenced by nature's attributes only. Four Canadian children $(8 \%)$ and one Slovak child $(\mathrm{n}=4 \%)$ attributed their feelings to activities they do in nature ( $p=.152$, two-tailed, $d f=1$ ) (see Table I9). Thirteen out of 24 Canadian participants (54\%) and 13 out of 26 Slovak participants (50\%) attributed their feelings to both, the activities in nature and nature's characteristics.

The following section presents children's statements about their feelings. The section is divided into feelings influenced by nature attributes and activities in nature.

\section{Feelings Influenced by Nature Attributes}

Children articulated feeling good in nature, as they liked nature's attributes, such as colours, smell, size or having plants. The following are few examples of children's responses.

\section{Canada}

Happy. Because it's so beautiful (Nadia, 6)

Happy, because of the different colours (Alie, 6)*

\section{Slovakia}

Good. Because there is the trees, there, they smell good (Roxana, 7)

Good. Because, it is everything so pretty (Marek, 7) 


\section{Feelings Influenced by Activities in Nature}

Children's feelings towards nature were influenced by activities children engaged in while in nature. Even though only five children's feelings were influenced by activity only, half of the children in both cultures disclosed that both, the activities and nature characteristics, have an impact on their feelings.

\section{Canada}

I like that you feel free, it's fun, you can do whatever you want, like climb trees, do fun stuff (Mary, 7)

Because I'm having fun, which makes me happy (Steve, 8)

\section{Slovakia}

Because you can do all kinds of things (Monika,7)

Very good. I can explore a little bit of nature (Tibor, 7)

The above quotations demonstrate the similarities in Canadian and Slovak children's responses in regard to liking nature due to activities they do in nature. However, some cultural variations were noted, as only Canadian children talked about liking nature for the health benefits. Sandra from Canada clarified her positive attitude towards nature in this dialogue:

Researcher: What do you like about nature?

Sandra: I like the flowers and I like the nature Researcher: Why do you like it?

Sandra: It's healthy, leaves makes you breathe and it's good to stay outside.

\section{Research Hypotheses}

\section{$\mathrm{H}_{1}$ : Direct Experiences with Nature in Children's Drawings}

It was hypothesized that "There will be differences between children from Canada and Slovakia regarding the number of children drawing direct experiences with nature." The quantitative data were analyzed by using SPSS (Version 20.0). The Chi-square Goodness of Fit test was used to compare Canadian and Slovakian children's drawings of direct experiences with 
nature. A majority of children drew direct experiences while in nature $(n=29 ; 56 \%)$. Fifteen Canadian children (58\%) and fourteen Slovak children (54\%) drew their direct experiences with nature, as shown in Figures 8 and 9. These findings were not significantly different $(p=.853$, two-tailed, $d f=1)$ (see Table I10).

Figure 8

Direct Nature Experience

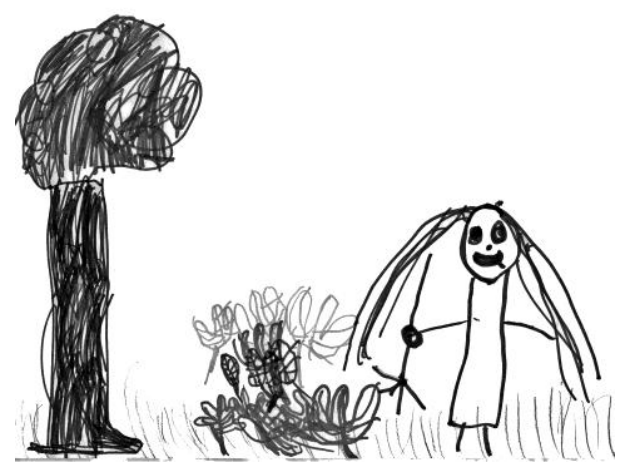

Figure 8. Diana, 5, Canada. Raking the leaves.
Figure 9

\section{Direct Nature Experience}

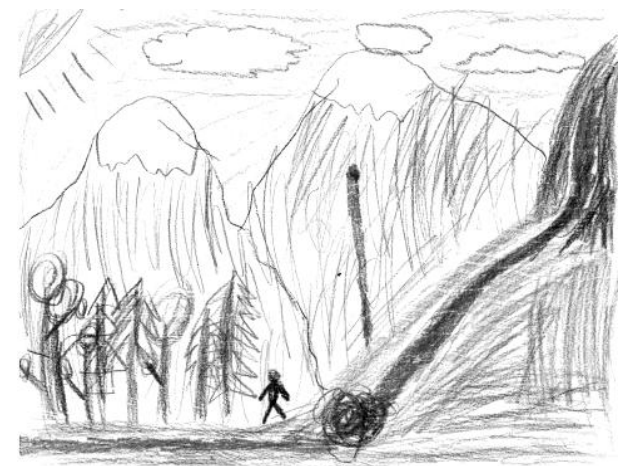

Figure 9. Marek, 7, Slovakia.

Walking in the forest.

\section{$\mathrm{H}_{2}$ : Natural Elements in Children's Drawings}

It was also hypothesized that "There will be differences in the number of different types of identifiable natural elements in the Canadian and Slovak children's drawings." The 2-tailed Ttest compared Canadian and Slovakian children's drawings in terms of the number of types of natural elements. There was no significant difference $(p=.680, d f=50)$ between the children's drawings in the two settings. Children from Slovakia included 129 natural items $(M=4.9615$, $S D=2.30618)$ and Canadian children included 136 natural elements $(M=5.2308, S D=2.37163)$ (see Table I11). For examples of children's drawings see Figures 10 and 11. 
Figure 10

Number of Natural Elements

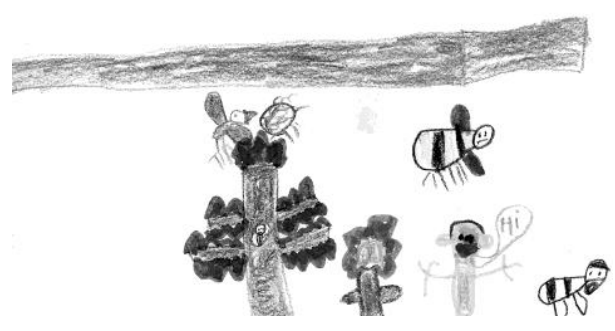

Figure 10. Sam, 7, Canada, Looking at nature. Count of 8 natural elements: Clouds, a bird, a bird nest, a tree, a squirrel, a flower, a bee, a racoon.
Figure 11

\section{Number of Natural Elements}

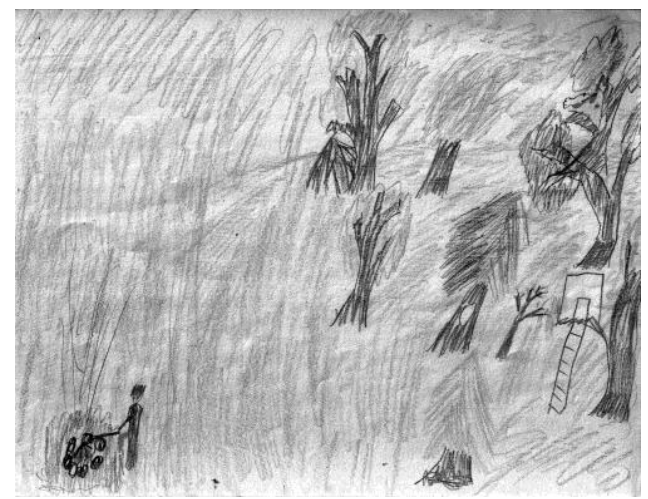

Figure 11. Martin, 8, Slovakia, making Campfire. Count of 8 natural elements: Grass, pine trees, leaf trees, dirt, rocks, bird, a bird nest, twigs.

\section{Additional Findings from Children's Drawings}

Children's drawings were examined in terms of what the most common element in their illustrations was. Differences were noticed as 14 Canadian children included flowers while only six Slovakian children did. On the other hand, seven Slovakian children drew pine trees and only one Canadian child did. Children's illustrations were further examined as to the number of children that drew trees. In total, $85 \%(n=44)$ children included trees in their drawing. The same number of children in Canada $(\mathrm{n}=22)$ as well in Slovakia $(\mathrm{n}=22)$ included trees in their images.

Furthermore, drawings were examined to see if children included water in their drawings. In total, 13 (25\%) children included water. Seven Slovakian children and six Canadian children drew water. After examining the images, there were differences as to what type of water the children drew. Four out of five Canadian children drew watering plants or spraying with a hose, while only one drew a river and one drew rain. This is in contrast to the five out of seven 
Slovakian children who included rivers or ponds. One Slovak child included a water well, and only one included watering plants (see Figures 12 and 13).

Figure 12

Water in Children's Drawings

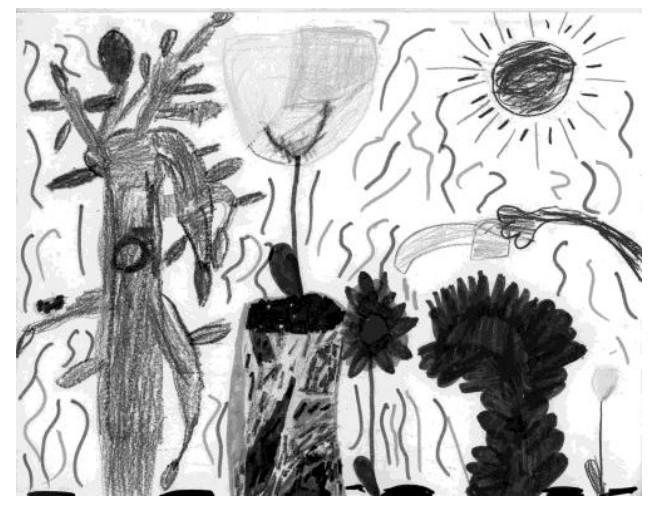

Figure 12. Lily, 6, Canada.

Watering plants with a hose and sprinkler.
Figure 13

Water in Children's Drawings

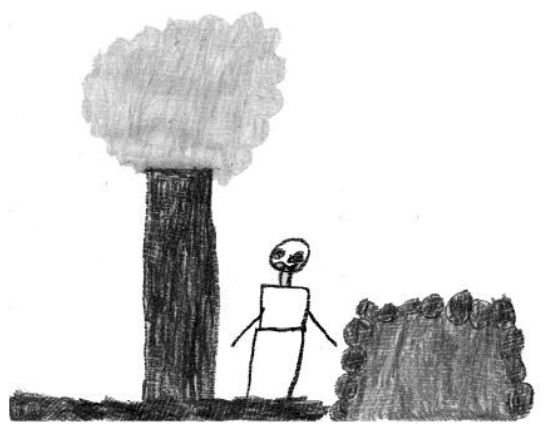

Figure 13. Palo, 6, Slovakia. By the pond catching frogs.

To further examine the number of natural elements in the drawings, the Chi-square test of Association helped to analyze the data. The levels of natural items in the drawings were categorized as low (1-4 elements), medium (5-8 elements) and high (9-12 elements). There were no significant differences between the Canadian and Slovak children $(p=.828$, two-tailed, $d f=2)$ (see Table I12). In the Canadian setting, half of the children $(\mathrm{n}=13,50 \%)$ drew between $5-8$, or a medium number of items of nature, and in the Slovakian setting half of the children $(\mathrm{n}=13,50 \%)$ also drew $5-8$, or a medium number of natural elements.

The number of types of natural elements in children's drawings were compared with the number of types of non-natural elements using a 2-tailed T-test. There were no significant variations between the children's drawings in the two countries. All together, children from Canada included six non-natural elements $(M=.2308, S D=.65163)$, while the total number of 
non-natural elements included by the children from Slovakia were seven $(M=.2692, S D=$ .53349) $(p=.817, d f=50)$ (see Table I13).

Lastly, the results revealed the differences between Canadian and Slovakian children regarding the most common drawn direct activity in their drawings. The most common direct activity in Canadian children's illustrations was gardening, as six children depicted gardening in nature. On the other hand, the most common direct activity among Slovakian children was walking, as four children illustrated walking in nature.

\section{Summary of findings}

In summary, with the exception of picking food and tanning, there were no statistically significant cross-cultural differences in the children's relationship with nature. However, qualitative variations between Canadian and Slovakian children were observed. See Tables 14 and 15 for a quick summary of the results.

Table 14

Summary of Qualitative Results

\begin{tabular}{|c|c|c|}
\hline Research Questions & Similarities & Differences \\
\hline Definition & $\begin{array}{l}\text { Living things } \\
\text { Non-living things } \\
\text { Nature is outside }\end{array}$ & $\begin{array}{l}\text { Slovakian children referred to } \\
\text { specific outdoor spaces (i.e. } \\
\text { forest). }\end{array}$ \\
\hline Experiences & $\begin{array}{l}\text { Direct } \\
\text { Playing games (i.e. hide-and- } \\
\text { seek) } \\
\text { Building with snow, sand } \\
\text { Walking } \\
\text { Running around } \\
\text { Relaxing in nature (Laying down) }\end{array}$ & $\begin{array}{l}\text { Canadian children have picnics } \\
\text { in nature while Slovakian } \\
\text { children cook food on a } \\
\text { campfire. }\end{array}$ \\
\hline & $\begin{array}{l}\text { Indirect } \\
\text { Playing in organized sports } \\
\text { Playing in unorganized sports } \\
\text { Relaxing in nature (Resting) }\end{array}$ & $\begin{array}{l}\text { More Slovakian children tan in } \\
\text { nature than Canadian children. }\end{array}$ \\
\hline
\end{tabular}


Children learn in nature

Feelings

Good and happy
Relaxed

Free

Fear of animals

Children's feelings are influenced by

nature's attributes and by the

activities children do in nature.
Canadian child uses technology to learn about nature, whereas Slovakian child uses images of nature to learn about nature.

Don't like bugs and plants that hurt.

Table 15

Summary of Quantitative Results

\begin{tabular}{llll}
\hline & Hypotheses & Supported & Refuted \\
\hline H1 & $\begin{array}{l}\text { There will be differences } \\
\text { between children from Canada } \\
\text { and Slovakia regarding the } \\
\text { number of children drawing } \\
\text { direct experiences with nature. }\end{array}$ & No significant differences \\
& & \\
H2 & $\begin{array}{l}\text { There will be differences in the } \\
\text { identifiable types of natural } \\
\text { elements in the Canadian and } \\
\text { Slovakian children's drawings. }\end{array}$ & No significant differences \\
\end{tabular}




\section{CHAPTER 5: DISCUSSION}

The aim of this research was to compare 5 to 8 year old children from two countries and their relationship with nature. More specifically, a cross-cultural comparison was conducted with 52 children from Canada and Slovakia. The study sought to examine how children define nature, as well as study children's attitudes towards and experiences in and with it. Children were asked to draw a picture of nature and themselves doing something in it. Additionally, they were interviewed about their feelings and the activities they do in nature. Lastly, children were shown four images of nature. These served to further facilitate a discussion about the children's feelings and activities in nature. The collected data were analyzed by a mixed method research design. This chapter is presented in five sections: Children's definitions of nature, children's experiences in nature and their feelings about nature, children's drawings of direct experiences in nature and natural elements in the children's drawings. It is important to keep in mind that these findings need to be understood within the context of this study. Given the sample size, caution should be exercised when generalizing.

\section{Definition of Nature}

Defining nature is a contentious issue. Currently, there is no agreement among scholars about the definition of nature (Clayton, \& Myers, 2009). In general, the disagreement revolves around what elements are regarded as natural, whether humans are part of nature, and at what point humans' manipulation of their surrounding is not nature. For these reasons, it is crucial to understand the children's concept of nature and examine it from their perspective in a given context. The Canadian children's definition was compared with Slovakian children. This comparison served not only to establish the children's understanding of nature and their relationship with it, but also to explore whether these conceptions are different across cultures. It 
is important to note that currently a limited amount of research exists regarding the cross-cultural comparison of young children's definition of nature.

Evident from this research is that children in both cultural settings have a positive relationship with nature, since children as young as 5-years-old had knowledge about different organisms and elements in nature. The results from this research support Samuelsson and Pramling's (2009) study conducted with young children in Sweden. They found that preschool children had a conception of complex phenomena like nature (Samuelsson, \& Pramling, 2009). Out of all the children in this study, only one child did not define nature. This means that the majority of young children had some experience with nature, thus, are in the process of building a connection with it.

In this study there were no significant cross-cultural differences concerning the children's ability to define nature. Children in Canada and Slovakia were able to respond either to the direct question "What is nature?" or were able to elaborate on "Where do you see nature?" Canadian and Slovakian children defined nature as living things, such as animals, trees and plants and associated nature as being outside. This was apparent, as all children drew activities that took place outdoors. This research supports Aaron and Witt's (2011) research findings, which showed that fifth-grade minority students from Houston defined nature as having natural elements, while identifying these elements as being outside. Unlike Aeron and Witt's (2011) study, some children from Canada and Slovakia also believed that nature is inside. Nature being inside coincides with Phenice and Griffore's (2003) study, where 52\% of 2-6 years-old children from the United States indicated nature being inside.

The results revealed children's ability to recognize that nature consists of individual organisms and elements (e.g., trees, animals, rocks). Children from Slovakia, in addition to 
identifying individual items, talked about nature in terms of specific places (e.g., forest). It is possible that the variations may have been a result of cultural perception and an understanding of what nature is. Interestingly, the most identified nature component was trees. Dr. David Suzuki, a Canadian environmental expert, also defined nature as "trees" (Ghomeshi, 2013). It is unclear why so many children included trees in their definition, but what is clear is that trees are abundant in both contexts. Perhaps, the prevalence of trees in the children's environment could be the explanation.

Children in Canada and Slovakia not only considered trees as nature but also understood the important ecological function trees have. Steve from Canada commented that trees are "Stuff that helps us, like, live. Like, gives us oxy...trees gives us oxygen.” Similarly, Riki from Slovakia suggested that trees are important "because tree gives oxygen." This is a significant finding, as children in both cultures recognized the importance of trees for human survival. It appears that the children's conception of nature is similar despite the different cultural contexts.

It is important to understand the human-nature relationship and where people fit in. If human's are engaged, there is a positive relationship. This concept is still developing in very young children (Phenice, \& Griffore, 2003). When examining this understanding crossculturally, no significant differences were found. Some children from Canada and Slovakia included and some children excluded humans in their nature definition. Their explanations for humans' inclusion revealed similar results. Children from both cultures perceived humans as nature because they live and because people were physically present in the nature.

Vining, Merrick, and Price (2008) found that 77\% of adults from the United States believed that humans are part of nature, while only $12 \%$ considered being separate from nature. The most common reason for being part of nature was human-nature interdependence and 
humans being biological organisms, while most prevalent answer for being separate was the lack of humans' physical presence in nature. Similar results were noted in this study. A few children commented that humans were not part of nature. The Canadian children did not elaborate. Some Slovakian children reasoned that people are not plants, nature is where animals live, and people are destroying nature, and thus cannot be part of it. Although, cross-cultural conclusions could not be drawn as to why children excluded humans from nature, it is certain that children in both countries are still developing their understanding of where people fit in the human-nature relationship.

Although many similarities within the children's conceptions about nature were identified, some variations have been noted. While a majority of children in both countries defined nature in terms of living things, a few children also included man-made structures. Considering man-made structures as nature leads to a children-nature disconnection, as there is no differentiation between the natural world and the man-made world. Consequently, children consider an indoor sedentary lifestyle as being in nature. This false notion increases the childnature disconnection.

It was observed that more Slovakian children than Canadian children defined nature as human-made. However, statistically these differences were not significant. A study conducted by Ma (2009) found that Chinese adults also include man-made artifacts into their definition of nature. Contrary to Ma (2009), Shepardson's (2005) investigation of seventh through ninth grade students' conceptions of the environment revealed that students from the United States excluded man-made structures from their drawings. These findings reiterate the complexity of defining nature and the lack of consensus. 
Magrath (2009) suggests that one's definition of nature is influenced by beliefs, values, social and cultural circumstances, as well as by knowledge. Contrary to Magrath (2009), the evidence in this study indicates that there were no significant cultural differences concerning how 5-8 years old children from Canada and Slovakia defined nature. The findings revealed many similarities between the two cultures. This study was tightly controlled through the use of children of the same ages, who lived in the largest urban cities with similar topography and climate. It was expected that when the sample and the environment were similar, any differences in children's responses were more likely be a result of cultural influence.

Since no significant variations were observed between the Canadian and Slovakian children in this study, culture did not influence the children's conception of nature. The children's ability to define nature also suggests that children from Canada and Slovakia are being exposed to nature and thus are given the opportunity to build connections with it. This prompts the questions: If culture did not affect the children's understanding of nature, what did and why are the children's perceptions the same between these two cultures?

\section{Children's Experiences in Nature}

Existing literature suggests that contemporary children "suffer" from "nature-deficit disorder," a term coined by Richard Louv (2005, p.36). Even though nature-deficit disorder is not a medical term, the expression suggests that the lack of direct nature experiences will alter human health. Turner, Nakamura and Dinetti (2004) implied that urban populations live in "biological poverty" (p.588), which may further contribute to a human-nature disconnection. Contrary to these claims, results from this study revealed that young children are connected to nature. Canadian and Slovakian children experience nature first-hand and interact with it through direct manipulation and activities, such as collecting artifacts (e.g., shells, sticks), building 
structures (with snow or sand) or walking in the forest. However, this study did find that there were some differences in direct nature experiences between children from Canada and Slovakia.

Previous empirical evidence revealed that experiences in nature vary according to ethnicity (Ozguner, 2011; Payne, Mowen, \& Orsega-Smith, 2002). Research on preferences of experiences in nature found that the American Hispanic population preferred nature programs that focused on families (California State Parks, 2005). In another study conducted by Payne, Mowen and Orsega-Smith (2002), the authors found that Caucasian populations preferred individualistic activities such as hiking and camping in remote places such as national parks.

This study did not investigate ethnic variations, but rather examined the cultures in their geographical, political and social circumstance. Maudsley (2007) views culture as a strong influence on children's activities in nature. Maudsley's statement was confirmed, as differences between Canadian and Slovakian children's activities were found. Qualitative data revealed that children from both cultures engaged in direct nature experiences, such as walking in the forest or mountains, food gathering, or swimming in a lake. The differences were apparent when closely examining specific activities in nature, such as gardening and eating food.

Results showed that Slovakian children mentioned gathering fruits and mushrooms more often and mentioned more different types of fruits than their Canadian counterparts. Moreover, several Slovakian children engaged in direct nature experiences, as they described making campfires and cooking meals. This activity required children to gather wood, as well as cook. This was in contrast to the indirect experiences of Canadian children who described having a picnic in nature. A picnic is not considered a direct experience as the children eat prepared food and do not engage or manipulate the surrounding nature directly. 
Similarly, Jay and Schrami (2009) identified cultural differences between Turkish people who preferred group activities, such as barbequing and playing soccer, and Balkan and RussianGermans who engaged more in individual activities, such as hiking and picking fruit. Likewise, cultural variations were identified by Peters et al. (2010). They found that having picnics and barbeques is more significant to non-Western immigrants (Turkish and Moroccan people) than to local Dutch people (Peters et al., 2010). That children in Slovakia mentioned having different nature experiences suggests that cultural norms and values influence how children interact with nature (Peters et al., 2010).

Wells and Lekies (2006) claimed playing in woodlands has a more lasting effect on children than engaging in cultivating activities such as gardening. Even though this study did not investigate the effects of individual activities in terms of the long-term effect, it was evident from the children's interviews that children received great satisfaction from gardening. Angela from Canada drew a picture of herself gardening and said, "I like to garden" and "I like helping plants and I also like to go outside." Likewise, Clayton (2007) revealed the benefits of gardening as being relaxing, looking at nature, and spending time outside. Cross-cultural variations concerning the children's enjoyment of gardening were not found, as all children displayed a pleasure and enthusiasm when talking about their gardening experience. The significance of this finding is that children in both countries recognized the benefits of gardening, thus building a positive relationship with nature.

A cultural gender dissimilarity in gardening as an activity was noted. Only girls in the Canadian context talked about their gardening experiences, while both, boys and girls in Slovakia discussed it. Berry et al. (2011) proposed, "Gender is an effect and a cause of socialization at the same time" (p.48). The socialization is culturally transmitted in order to 
purposefully shape a person's behavior (Berry et al., 2011). Cultural differences may account for why Canadian children talked about watering plants, weeding, and raking leaves only, while Slovakian children, specifically boys, also talked about mowing grass and clipping branches. Cultural differences in gardening experiences aside, these findings support the idea that children in both countries are building a positive connection with nature through direct nature experiences.

Additionally, children in both countries commented on the peaceful and calming activities they can do in nature. For example, Canadian children described nature as a place where they can be "laying down." Similarly, Slovakian children mentioned, "sometimes I rested there." These findings are significant as they demonstrate that regardless of culture, contemporary urban Canadian and Slovakian children recognized the benefits of nature and seek these qualities of nature.

Nature provides multiple opportunities for children's cognitive development. The range of objects, e.g., trees, plants, animals and rocks, presents children with numerous opportunities for critical thinking and problem solving (Kellert, 2005). The finding that urban children acquire knowledge in nature has been supported by this research. Children in this study talked about identifying plant and animal species and problem solving when building with natural elements.

Differences between the Canadian and Slovakian children were observed in the children's learning. Children in Slovakia learned through direct interaction with nature. Recall the scenario with Mike who used a paper page with different animal track prints to match with prints found on the ground. It was a direct nature experience, as Mike made a conscious decision about the properties of the prints. Canadian children, in addition to learning through direct nature experiences, also identified learning through indirect ones. Natalia used a computer application 
to identify leaves in nature. A computer that identifies the species is considered an indirect activity as it is the computer that performs the "cognitive" processes. Berry et al. (2011) explained the learning differences between cultures as not only occurring socially, but also through using artifacts, such as mobile phones or computers constructed by their culture. As such, this demonstrates the different cultural values when interacting with nature.

This study's findings revealed that children in both cultural settings had close contact with nature. Even though children from both cultures directly interacted with nature, some differences in these encounters were observed. The cross-cultural variations in children's experiences with nature uncovered in this research may be a result of different cultural values and expectations. Knowing the positive effects of nature on children's health (Berman et al., 2012; Faber Taylor, \& Kuo, 2006; Maller, 2009) calls for making these nature experiences relevant. What makes them relevant and special "is the unique integration of culture with nature" (Kellert, 2005). Particularly, what is relevant in one cultural setting may or may not be relevant in another context. By providing multiple nature experiences, we acknowledge the cultural relevance and expand the benefits of nature to more children.

\section{Children's Feelings about Nature}

Canadian and Slovakian children's relationships with nature were explored by examining children's feelings about nature. To further understand the underlying cause of their emotions, children provided a rationale for their feelings. Generally, according to Kaplan and Kaplan (2002), humans tend to have preferences for natural environments. Even though this study did not investigate children's preferences, they were apparent: Children have positive feelings towards nature. This was consistent among the children from Canada as well as Slovakia. Overwhelmingly, all children identified feeling happy, good or relaxed in nature. 
These findings are consistent with Strife's (2008) study, where fifth grade students from Denver, Colorado commented they felt happy and peaceful. In this study, Canadian children talked about feeling happy, while Slovakian children identified feeling good. This happy/good difference could be a result of the language differences between the cultures (Berry et al., 2011). Nevertheless, the results from this study suggest that nature has a positive influence on children's emotional state regardless of the culture they are from and the children are cognizant of these feelings. This further demonstrates that Canadian and Slovak urban children in the study have established a positive relationship with nature.

In addition to feeling good and happy, children in both cultures identified feeling free. Similarly, the sense of freedom in nature was identified by Hougie (2010). While Hougie (2010) identified UK children feeling free due to the open spaces, children from Canada and Slovakia primarily referred to unstructured and unorganized play. The children's positive emotions towards nature were illustrated through statements such as feeling "free" and able to do "all kinds of things." This is worth noting, as children associate nature as a place where they are free of the constraints of society and daily structured activities. Many scholars found that contemporary children are increasingly engaged in structured activities, such as doing homework, play in organized sports, and are micromanaged by their parents (Clements, 2004; Louv, 2005; Skår, \& Krogh, 2009). Rosenfeld and Wise (2001) call this phenomenon "hyperparenting."

The children's statements in this study remind us that children seek self-directed activities, free of adult control and where they can experience freedom and independence. They also seek and appreciate the peace and quiet of nature. The results are noteworthy as both 
Canadian and Slovak children appreciate the freedom and tranquility aspects of nature and desire to build positive connections with nature.

Even though all children, in both settings identified having positive feelings towards nature, Canadian and Slovak children also talked about being fearful of nature. King, Hamilton and Ollendick (as cited in Heerwagen, \& Orians, 2002) implied that the fear of larger animals, such as wolf and bears, is common in children older than four years old, but diminishes around the age of 10. Furthermore, the authors illustrated that the fears of heights and darkness are based on evolutionary factors and are quite common among children. These fears will also dissipate with age (Heerwagen, \& Orians, 2002). The fear of nature may be perceived as a disconnection from nature; however, it is important to keep in mind that even negative emotions towards nature are a type of engagement with nature (Clayton, \& Myers, 2009).

Interestingly, even though all children in both cultures identified feeling happy/good, Laurie from Canada suggested feeling bored because there is no "fun stuff." Furthermore, Adam from Canada disliked nature, as there was "no cotton candy." In contrast, not one child from Slovakia mentioned being bored in nature or nature not having stimulating elements. Perhaps the differences are a result of different cultural values and children's expectations to be continuously entertained (Pain, 2006).

A fascinating discovery about children's relationships with nature is that their feelings towards nature were overwhelmingly positive. All children talked about feeling happy/good and liking nature. Cross-cultural researchers suggest that emotions are similar across cultures but are manifested differently (Berry et al., 2011). When examining why children felt happy/good in nature, 12 Slovakian children while seven Canadian were influenced by nature's properties (e.g., having trees and animals). However, when accounting for negative and positive feelings towards 
nature, the children's feelings in both cultural settings were equally influenced by activities the children do in nature as well nature's qualities. Consequently, there were no significant cultural variations influencing the children's feelings towards nature, thus culture was not the primary factor that influenced children's feelings towards nature.

What children do in nature and nature's characteristics are equally important. In other words, being in nature and not having opportunities to engage in meaningful experiences does not allow for establishing a positive relationship with nature. For example, being in a botanical garden might be visually stimulating; however, the lack of hands-on touching and manipulating the plants does not allow for creative and active exploration of the nature (Kellert, 2002). Likewise, participating in meaningful activities but in an unnatural setting provides children with the experiences, but it does not allow for a nature connection. In this study, children voiced that both the activities and nature qualities are important. It is essential that children be given time and space to be in nature, in order to establish a positive relationship with nature.

The children in both cultural settings, Canada and Slovakia, had positive emotions towards nature. They all talked about feeling happy or good. These positive feelings towards nature overwhelm the few negative experiences, such as being stung by a bee. Consequently, children, regardless of culture, desire the opportunity to freely and unencumbered with structure, explore and interact with nature.

\section{$\mathrm{H}_{1}$ : Children's Drawings of Direct Experiences in Nature}

Louv (2005) and other scholars indicated that U.S. and Canadian children's direct experiences with nature have started to decline. To explore whether these patterns are similar in other cultures, Canadian children were compared with Slovakian children. To explore the differences between Canadian and Slovakian children and their relationship with nature, 
children's drawings of their direct experiences were examined. Children who illustrated direct experiences with nature established a positive relationship with nature since they were interacting with nature directly. The results revealed that there were no differences in terms of how many children drew direct activities. The same number of children in Canada and Slovakia depicted direct experiences with nature. This means that children in both cultures established a similar connection with nature, where culture did not influence whether children engaged more in direct activities or not.

However, variations were found in the types of direct experiences with nature that were drawn by children. The most frequently drawn activity by Canadian children was gardening, while Slovakian children drew walking. According to Jay and Schrami (2009), members of different cultures use nature for different recreational purposes. Culture-specific activities are what differentiate the children's relationship with nature. In other words, children from Canada and Slovakia established positive relationships with nature, but how they were established was different. Consequently, culture played a role in the children's connection with nature.

\section{$\mathrm{H}_{2}$ : Natural Elements in Children's Drawings}

According to Clements (2004), children are spending less time in nature than the previous generation. This could result in children's diminishing awareness of the environment and disconnection from it. To understand children's awareness, and thus their relationship with nature, children's drawings were examined in terms of number of different natural objects in their illustrations. More natural elements depicted in children's drawings were thought to signify a deeper connection with nature, as children are aware of more aspects of nature. There were no significant differences found between Canadian and Slovakian children regarding the number of different natural elements in their drawings. Children from both countries drew similar quantities 
of natural items. The study's findings revealed that children from Canada and Slovakia have established similar relationships with nature, as they were aware of a similar number of natural items. As the environment in both cultures was similar (e.g., urban setting, similar topography and climate), this indicates that culture did not influence the children's understanding of their natural environment.

Conversely, culture did influence the specific components of nature children included in their drawings. Children from Canada and Slovakia included different items in their illustrations. For example, Canadian children drew more flowers, while Slovakian children drew more pine trees. Another cultural distinction between the children was a depiction of different types of water in their drawings. While Canadian children illustrated plant watering, Slovakian children included more rivers and ponds. Children in this study drew specific elements of nature, as these elements are important to the culture and because they are available within their environment. The significance of the results shows that culture plays a role in young children's connections with nature. Outside of the scope of this study, but an interesting future study consideration: Would children draw trees if trees were not present within their environment (e.g., desert)?

Interestingly, only one quarter of the children included water in their drawings. This corresponds with a quarter of children in Kalvaitis's and Monhardt's (2012) research. In both settings, Canada and Slovakia, water is a major feature of the environment. The city of Toronto, Canada, is beside Lake Ontario and the Danube River is threading through the downtown of Bratislava, Slovakia. It raises the question: Why did so few children include water in their drawings when water is a familiar feature of the landscape of their respective cities?

In conclusion, no cross-cultural variations have been identified concerning children's relationship with nature; however, cultural differences were apparent when examining how 
children engaged with it. Children in Canada and Slovakia demonstrated overwhelmingly positive feelings towards nature, while the experiences were somewhat culturally different. 


\section{CHAPTER 6: CONCLUSION}

The aim of this research was to compare 5 to 8 years old children from Canada and Slovakia and their relationship with nature. The children's relationship with nature was examined through understanding their definition of, experiences with and feelings towards nature. Photographs, semi-structured interviews and the children's personal drawings served to explore their connection with the natural world. Although no one study can explain all the complexities of cultural similarities and differences, this research further contributes to the debate on whether cultures are relative or universal, and provides insight into children's relationships with nature in different cultures. Previous research investigating relationships with nature tend to examine it primarily from an adult perspective or with older children. Currently, there are a limited number of recent studies exploring the cross-cultural comparison of children's relationship with nature. Thus, this work helps fill the gap in the research. It is important to note that when referring to Canadian and Slovakian children, reference is only made to the children that participated in the study.

The results revealed that there were no cultural differences in the children's relationship with nature; however, cultural differences were apparent in the way children constructed their relationship. In other words, how children from Canada and Slovakia defined nature and felt in nature was similar, but the way they engaged with nature was culturally different. Therefore, culture plays a role when establishing a connection with nature. The result that children have positive feelings in nature supports Edward O. Wilson's (1984) biophilia hypothesis that humans have an innate affinity to connect with nature.

Even though this research did not examine the quantity of direct encounters the children had with nature, it does demonstrate that children in Canada and Slovakia do have direct 
experiences with nature. These findings are important as nature positively affects the overall well-being of children. Children in both countries communicated liking trees, plants, being able to run around, pick food and have a place to relax. Therefore, children's nature experiences should consider all of these aspects while embracing cultural variations.

\section{Implications}

The results from this research suggest that children from Canada and Slovakia have positive relationships with nature. Children in the study enjoyed being in a natural setting regardless of their cultural background. Recognizing that children from various cultural backgrounds enjoyed being in nature and acknowledging nature's positive effects on their overall well-being can help guide adults, educators and government officials to work together to ensure that children can reap the benefits of nature for their healthy development. Therefore, it is recommended that children be provided with opportunities to spend time in nature, while making these nature encounters culturally relevant. Richard Louv (2005) in his book "Last Child in the Woods: Saving Our Children from Nature Deficit Disorder” provides several suggestions about how to engage young children with nature, including returning schoolyards to green spaces and creating nature schools.

\section{Limitations of the Study and Future Research}

Several limitations may affect the results of this study. First, the sample size was limited and only included a few schools in each country. Different findings might have been unveiled if a broader sample across the countries would have been used. Therefore, it is recommended future research be conducted with a larger sample.

Second, the samples in Canada and Slovakia did not have equally matched ages and genders of children. This may have resulted in the variations in the activities children 
participated in and reported. Due to the time constraints on the study, priority was given to maintaining a cultural comparison. Therefore, controlling the sample to use children of the same ages and gender in both countries would enhance future studies.

The third limitation was the presence of the researcher during the data collection. This presence may have induced children to be reserved and withholding or alternately wanting to "please" the researcher. This limitation can be challenging to overcome. It was mitigated by reminding the children that there are no right or wrong answers.

Fourth, the study occurred during the warm months of May and June, thus the children's responses might have been influenced by the seasonal aesthetic qualities of nature. Further research is needed to understand if children's relationships with nature yield different results during the winter months.

Furthermore, the countries compared in this study were similar in their topography and climate. It is essential to examine whether cultural similarities and differences could be found when the topography and environments are different (e.g., desert vs. tropical rainforest).

Children have an affinity to learn and explore nature. As such, these qualities must be cultivated with meaningful encounters with the natural world. As noted by Peter Kahn, Jr. (2002) "We must recognize our need for a more pristine and at times wild nature so that adults and children alike can experience it, construct concepts of ecological health and be nourished by it in body and mind" (p.114). 


\section{Appendices}

Appendix A

\section{Parental Recruitment Information}

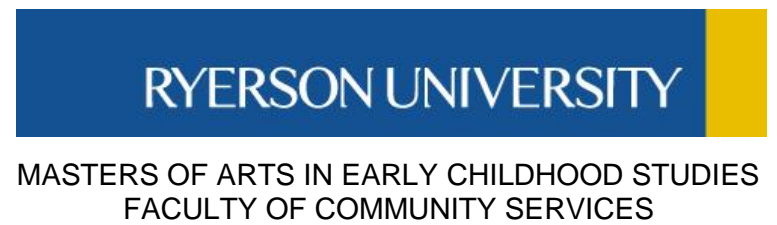

Recruitment Information

“The Influence of Culture on Children's Relationships with Natural Environments"

Dear Parent / Guardian,

Your child is being asked to participate in a research study. This letter is so that you are informed of the consent requirement for your child to be a volunteer participant.

I am a Masters student in the Ryerson University Early Childhood Studies program. I am conducting a research project entitled "The Influence of Culture on Children's Relationships with Natural Environments." My supervisor is Dr. Robert Rinkoff, a professor in the School of Early Childhood Studies at Ryerson University.

I am looking into the relationships children have with natural environments; more specifically, how children from two different regions of the world perceive natural environment as well as their attitudes towards it and participation in and with it. My focus is on children 4 to 8 years of age. The inspiration for my study is based on the notion that natural environments are beneficial for overall wellbeing, yet many of today's children are spending less time outdoors.

It is hoped that the proposed study will add to the body of knowledge and be of benefit to educators, early childhood practitioners, curriculum planners and policy makers. A better understanding of the differences and similarities in a cultural contexts can help tailor educational experiences for children.

I am looking for children that are:

- 4 to 8 years old.

- Children that are born in Canada.

The study explores whether relationships with a natural environment may be shaped by the country they were born in, and to where they live.

Participating children in the study will be asked to draw a picture of nature and participate in an interview that will explore their thoughts on nature. Children will be shown few photographs of nature and answer few questions about them. This process should take approximately 45 minutes. Class time may or may not be used, depending on the schools' preference and requirements. Children's names and name of the school will not be used. Some sample question:

- Do you know what nature is?

- What is your favorite thing to do in nature?

- What do you do in nature?

If you have any questions or concerns, please contact Andrea Donnell by e-mail adonnel@ryerson.ca or by Skype adonnel.ryerson. You may also contact Dr. Robert Rinkoff by phone at 416.979.5000 extension 6332, or by e-mail at rrinkoff@ ryerson.ca.

I would like to have your child participate in this study. If interested, please read and sign the document entitled "Ryerson University Consent Agreement for Parents and Guardians the 
Researcher's Copy." Please return the "Researcher's Copy" to your teacher in a sealed envelope whether or not want to participate by May 8, 2013. In addition to your approval, your child will be asked for his/ her assent.

Thank you for your time and interest.

Sincerely,

Andrea Donnell, B.A.

MA Candidate

Yeates School of Graduate Studies

Early Childhood Studies Program

Ryerson University

350 Victoria Street

Toronto, Ontario, Canada M4R 1H8

Telephone: 416.979.5000 extension 6332

E-mail: rrinkoff@ryerson.ca 


\section{Appendix B}

Parental Consent Agreement

RYERSONUNIVERSITY

MASTERS OF ARTS IN EARLY CHILDHOOD STUDIES

FACULTY OF COMMUNITY SERVICES

Consent Agreement

\section{"The Influence of Culture on Children's Relationships with Natural Environments"}

Your child is being asked to participate in a research study. Before you give your consent for your child to be a volunteer, it is important that you read the following information and ask as many questions as necessary to be sure you understand what your child will be asked to do.

Investigator: Andrea Donnell

I am a Masters student in the Ryerson University Early Childhood Studies program. My supervisor is Dr. Robert Rinkoff, a professor in the School of Early Childhood Studies at Ryerson University.

Purpose of the Study: This study is part of the Major Research Paper requirement of the Master of Arts Program in Early Childhood Studies. I am looking into the relationships children have with natural environments; more specifically, how children from two different regions of the world perceive the natural environment as well as their attitudes towards it and participation in and with it.

My focus is on children 4 to 8 years of age. Children from selected elementary schools in two countries are being asked to participate. I am seeking 50 children to be included in the study. The inspiration for my study is based on the notion that natural environments are beneficial for overall wellbeing, yet many of today's children are spending less time outdoors.

It is hoped that the proposed study will add to the body of knowledge and be of benefit to educators, early childhood practitioners, curriculum planners and policy makers. A better understanding of the differences and similarities in a cultural contexts can help tailor educational experiences for children.

Description of the Study: Your child will be shown few photographs of nature and answer few questions about them. It is anticipated to take 10-15 minutes. In addition, your child will be asked to draw a picture of nature and participate in an interview that will explore his/her thoughts on nature. The drawing session will take approximately 25-30 minutes. The times are approximate and it will vary from child-to-child. Some sample question:

- Do you know what nature is?

- What is your favorite thing to do in nature?

- What do you do in nature?

The study will take place in the school. The exact time and place will be determined with the school personnel.

Risks or Discomforts: It is possible that your child may be uncomfortable or wish to stop and may not be sure how to communicate this to the researcher. Therefore, prior to commencing the study, your child will be reminded that he/she can say "stop now" or "skip" or "no." Additionally, as the researcher I will be alert to non-verbal signs of discomfort and/or fatigue on the part of your child and will stop the activity immediately. 
Benefits of the Study: Your child may benefit from participating in this research by having his/her opinions validated within the context of this study. However, I cannot guarantee, that your child will personally receive any benefits from participating in this study. It is hoped that this study will provide educators with insight into how and why children interact with the natural environment. As a result, the study will add to the knowledge how educators can better tailor educational experiences for children in natural environments; however, it is not guaranteed.

Confidentiality: As part of the study, your child's identity will not be disclosed. Drawings and interviews will be given a number. To protect confidentiality the number will not be associated to a child's name. The number will be used to identify documents, drawings and recordings. The child's identity will be de-identified. The findings from this research will be presented in summary form. Some children's quotes and drawings will be used to illustrate findings in the report. The intention is to represent the findings that best reflect the children's statements and opinions. All quotes and drawings will be presented without children's names. Additionally the name of the school will not be used.

Children's interviews will be voice recorded in order to accurately capture all the answers. If you or your child do not wish to audio record the interview, I will only write down children's responses.

All data will be retained in secured storage for five years. Only the researcher and research supervisor will have access to it. After five years, all data will be shredded or deleted.

There are some limitations to confidentiality. The law requires that the proper authorities be notified if it is suspected that a child is in need of protection, or if it is suspected that a child might harm him/herself or someone else. However, questions in this study are only about children's relationship with nature.

Costs and/or Compensation for Participation: There will be no cost for children to participate in this study. Children that will participate in the study will receive a package of pencils.

Voluntary Nature of Participation: Participation in this study is voluntary. Your choice whether or not your child will participate in this study will not jeopardise future relationships with Ryerson University or your child's childcare. If you agree that your child may participate, your child may refuse to answer any question and is free to withdraw from the study at any time without penalty. Your child will be asked for his/her assent. Your child will not have to participate in the study.

Questions about the Study: If you have any questions about the research now, please ask. If you have questions later about the research, you may contact:

The principal investigator: Andrea Donnell

Email: adonnel@ryerson.ca

Skype name: adonnel.ryerson

Research Supervisor: Dr. Robert Rinkoff

Department: Early Childhood Studies, Ryerson University

Email: rrinkoff@ryerson.ca.

Telephone: 416.979 .5000 extension 6332

If you have questions regarding your rights as a human subject and participant in this study, you may contact the Ryerson University Research Ethics Board for information.

Research Ethics Board

C/o Office of the Vice President, Research and Innovation

Ryerson University

350 Victoria Street

Toronto, ON M5B 2K3

416-979-5042 


\section{Agreement:}

Your signature below indicates that you have read the information in this agreement and have had a chance to ask any questions you have about the study. Your signature also indicates that you agree that your child may participate in the study and have been told that you/your child can change your mind and withdraw your or his/her consent to participate at any time.

You have been given a copy of this agreement.

You have been told that by signing this consent agreement you are not giving up any of your legal rights.

Child's Name (please print)

Age of the child

Gender of the child

Parent's/ Guardian's Signature

Date

Signature of Investigator

Date

If you are willing to have your child to be audio recorded, please sign on the line.

Yes, you have my permission to audio record the interview session 


\section{Appendix C}

\section{Child Assent Agreement}

\section{RYERSONUNIVERSITY}

MASTERS OF ARTS IN EARLY CHILDHOOD STUDIES

FACULTY OF COMMUNITY SERVICES

\section{Child's Assent Agreement}

\section{"The Influence of Culture on Children's Relationships with Natural Environments"}

My name is Andrea Donnell and I am a student at Ryerson University. I am doing a special research project about what are children's relationships with nature in different countries and I need your help. I want to know how you feel about nature and what do you do in there. I will be asking you some questions. Your parents have said it is okay for you to do this but if you don't want to, no one will be upset or angry.

It's OK by me that:

1. I will talk to the researcher Andrea Donnell

2. I will draw a picture and talk about nature and my experiences in nature

3. I will look at some photographs about nature and answer few questions about nature

4. Things I talk about will be written down

5. Things I talk about will be recorded by a voice recorder

6. I can skip a question by saying "skip" or stop the study by saying "I am done now"

7. I can end being part of the study at anytime without any questions being asked.

8. It's okay to ask my teacher to be with me when we are working.

My name

My signature or special mark

Today's date 


\section{Appendix D}

\section{Exploratory Questions}

1. Do you know what nature is?

2. What is nature?

3. Where do you see nature? 
Appendix E

Drawing Activity

Direction: Draw a picture of nature and yourself doing something in nature. 


\section{Appendix F}

\section{Interview Guide}

1. Tell me about your drawing.

2. Is this a real or imaginary place? Where is this place? Have you been there?

3. What do you usually do after school?

4. What do you usually do on the weekends?

5. What do you do in nature? Why?

6. How often do you go to nature?

7. Do you spend enough time in nature? Why?

8. With whom do you go to natures with?

9. What is your favorite thing to do in nature? Why?

10. How do you feel when you are in a nature? Why?

11. What do you like about nature? Why?

12. What do you dislike about nature? Why?

13. How should people interact with/ or behave in natures? Why?

14. Do you think natures are important to people? Why?

15. Are people a part of the nature? Why?

16. Can anything harm nature or does nature stay the same?

17. How should people treat natures? Why? 


\section{Appendix G}

\section{Interview Guide: Photographs of Nature}

1. Have you have been in a similar place? Why?

2. How do you feel in it? Why?

3. What do you do in place like this? Why?

4. What do you like about this place? Why?

5. What do you dislike about this place? Why?

6. With whom do you go to nature?

7. What is your favourite thing to do in nature? Why?

8. Do you want to tell me something I have not asked?

9. Do you want to ask me a question? 


\section{Appendix H}

\section{Photographs of Nature}

Figure 1

Image 1: Green Fields

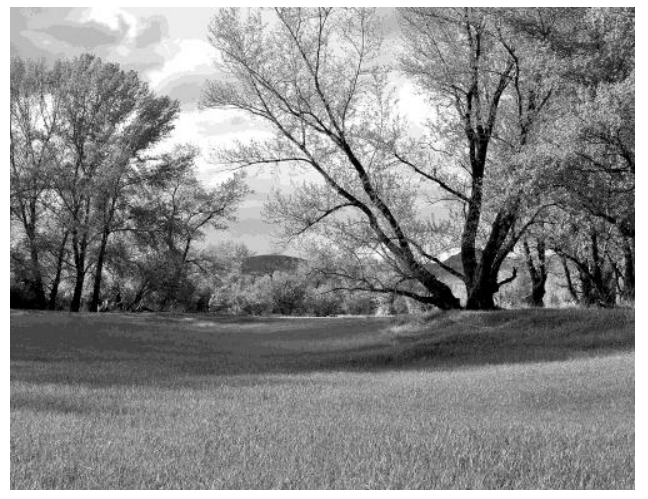

Figure 1. Koskina, L. (2007-2013). Green fields.

Figure 3

Image 3: Beach

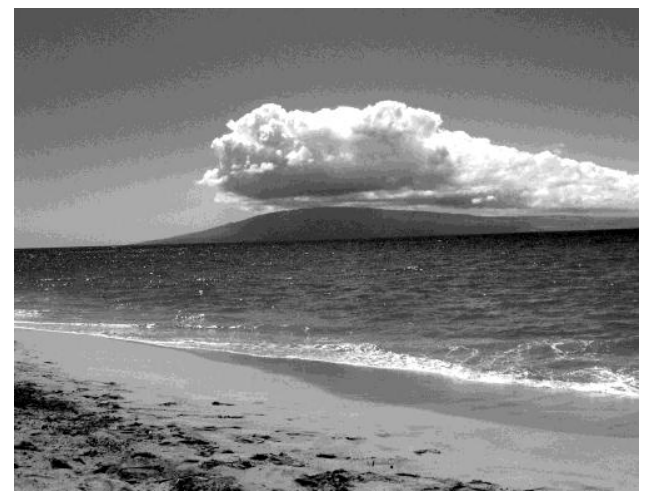

Figure 3. Beach.
Figure 2

Image 2: Forest

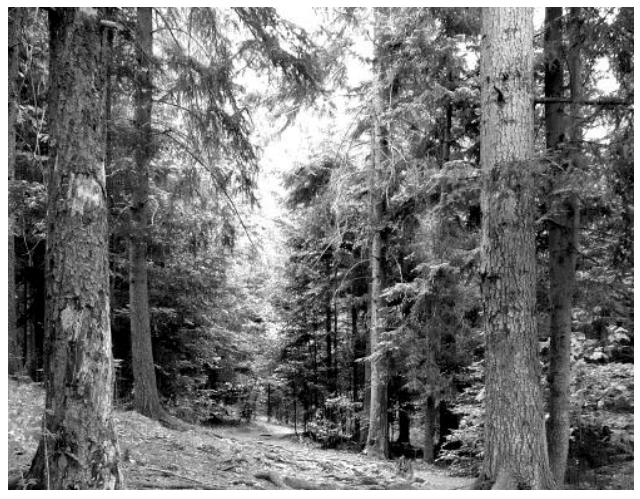

Figure 2. Forest
Figure 4

Image 4: Mountains

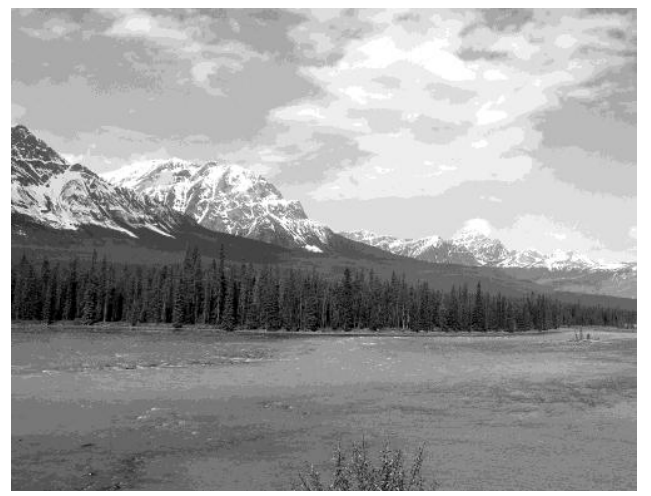

Figure 4. Mountains. 


\section{Appendix I}

Tables

Table 1

Direct Experiences with Nature

\begin{tabular}{llcc}
\hline Direct Experience & Examples & Canada & Slovakia \\
\hline Camping & Camping in nature & 1 & 0 \\
Eating & Making a campfire & 0 & 3 \\
Exploring nature & Bugs, plants & 0 & 1 \\
Food picking & Berries, fruit, mushroom & 1 & 2 \\
Gardening & Raking, planting, watering & 6 & 1 \\
Playing with plants & Picking flowers, catching & 4 & 1 \\
$\quad$ and animals & animals & & \\
Playing & Hide-and-seek, tag & 2 & 5 \\
Walking & Hiking, walking in nature & 1 & 4 \\
\hline Total & & 15 & 17
\end{tabular}

Table 3

Natural Non-Living Things

\begin{tabular}{lll}
\hline \multicolumn{1}{c}{ Canada } & \multicolumn{1}{c}{ Slovakia } \\
\hline Non-Living Things & $\begin{array}{l}\text { Air, cloud, dirt/soil, rocks, } \\
\text { sticks, rainbow, sky, snow, rain, } \\
\text { water, woodchips }\end{array}$ & $\begin{array}{l}\text { Air, clouds, rocks, sky, sticks, } \\
\text { water }\end{array}$ \\
\hline Total & 11 & 6
\end{tabular}

Table 4

Number of Children Picking Food

\begin{tabular}{lcccccc}
\hline & Observed N & Expected N & Residual & Chi-Square & df & Asymp. Sig. \\
\hline Canada & 2 & 7.0 & -5.0 & & \\
Slovakia & 12 & 7.0 & 5.0 & & \\
Total & 14 & & & $7.143^{\mathrm{a}}$ & 1 & .008 \\
\hline a. 0 cells $(0.0 \%)$ & have expected frequencies less than 5 . The minimum expected cell frequency \\
is 7.0.
\end{tabular}


Table 5

Number of Children Eating Food in Nature

\begin{tabular}{lcccccc}
\hline & Observed N & Expected N & Residual & Chi-Square & df & Asymp. Sig. \\
\hline Canada & 5 & 7.5 & -2.5 & & & \\
Slovakia & 10 & 7.5 & 2.5 & & & \\
Total & 15 & & & $1.667^{\mathrm{a}}$ & 1 & .197 \\
\hline
\end{tabular}

a. 0 cells $(0.0 \%)$ have expected frequencies less than 5 . The minimum expected cell frequency is 7.5

Table 6

Number of Children Tanning in Nature

\begin{tabular}{lcccccc}
\hline & Observed N & Expected N & Residual & Chi-Square & df & Asymp. Sig. \\
\hline Canada & 1 & 5.0 & -4.0 & & & \\
Slovakia & 9 & 5.0 & 4.0 & & & \\
Total & 10 & & & $6.400^{\mathrm{a}}$ & 1 & .011 \\
\hline
\end{tabular}

a. 0 cells $(0.0 \%)$ have expected frequencies less than 5 . The minimum expected cell frequency is 5.0 .

Table 8

Reasons for Feelings Influenced by Nature Qualities

\begin{tabular}{lcccccc}
\hline & Observed N & Expected N & Residual & Chi-Square & df & Asymp. Sig. \\
\hline Canada & 7 & 9.1 & -2.1 & & & \\
Slovakia & 12 & 9.9 & 2.1 & & & \\
Total & 19 & & & $.930^{\mathrm{a}}$ & 1 & .335 \\
\hline
\end{tabular}

a. 0 cells $(0.0 \%)$ have expected frequencies less than 5 . The minimum expected cell frequency is 9.1 .

Table 9

Reasons for Feelings Influenced by the Activity

\begin{tabular}{lcccccc}
\hline & Observed N & Expected N & Residual & Chi-Square & df & Asymp. Sig. \\
\hline Canada & 4 & 2.4 & 1.6 & & & \\
Slovakia & 1 & 2.6 & -1.6 & & & \\
Total & 5 & & & $2.051^{\mathrm{a}}$ & 1 & .152 \\
\hline
\end{tabular}

a. 2 cells $(100.0 \%)$ have expected frequencies less than 5 . The minimum expected cell frequency is 2.4 . 
Table 10

Number of Children Drawing Direct Nature Experiences

\begin{tabular}{lcccccc}
\hline & Observed N & Expected N & Residual & Chi-Square & df & Asymp. Sig. \\
\hline Canadian & 15 & 14.5 & .5 & & & \\
Slovakian & 14 & 14.5 & -.5 & & & \\
Total & 29 & & & $.034^{\mathrm{a}}$ & 1 & .853 \\
\hline
\end{tabular}

a. 0 cells $(0.0 \%)$ have expected frequencies less than 5 . The minimum expected cell frequency is 14.5.

Table 11

Number of Natural Elements in Children's Drawings

\begin{tabular}{llcccccc}
\hline & Location & $\mathrm{N}$ & Mean & $\begin{array}{c}\text { Std. } \\
\text { Deviation }\end{array}$ & $\begin{array}{c}\text { Std. Error } \\
\text { Mean }\end{array}$ & df & Sig. (2-tailed) \\
\hline Natural & Canada & 26 & 4.9615 & 2.30618 & .45228 & & \\
Elements & Slovakia & 26 & 5.2308 & 2.37163 & .46511 & & \\
& & & & & & 50 & .680 \\
\hline
\end{tabular}

Table 12

Level of Natural Elements

\begin{tabular}{llcccccc}
\hline & & \multicolumn{3}{c}{ Level of Natural Elements } & Total & df & Asymp. Sig. \\
& & $1-4$ & $5-8$ & $9-12$ & & & (2-sided) \\
\hline \multirow{2}{*}{ Location } & Canada & 12 & 13 & 1 & 26 & & \\
Total & Slovakia & 11 & 13 & 2 & 26 & & .828 \\
\hline
\end{tabular}

a. 2 cells $(33.3 \%)$ have expected count less than 5. The minimum expected count is 2.00 .

Table 13

Number of Non-Natural Elements in Children's Drawings

\begin{tabular}{llcccccc}
\hline & Location & $\mathrm{N}$ & Mean & $\begin{array}{c}\text { Std. } \\
\text { Deviation }\end{array}$ & $\begin{array}{c}\text { Std. Error } \\
\text { Mean }\end{array}$ & df & Sig. (2-tailed) \\
\hline Natural & Canada & 26 & .2308 & .65163 & .12779 & & \\
Elements & Slovakia & 26 & .2692 & .53349 & .10463 & & \\
& & & & & & 50 & .817 \\
\hline
\end{tabular}




\section{References}

Aaron, R. F., \& Witt, P.A. (2011). Urban students' definitions and perceptions of nature. Children, Youth and Environments, 21(2), 145-167.

Aguirre-Bielschowsky, I., Freeman, C., \& Vass, E. (2012). Influences on children's environmental cognition: A comparative analysis of New Zealand and Mexico. Environmental Education Research, 18(1), 91-115.

Attitude. (1996). In Webster's Encyclopedic unabridged dictionary of the English language. New York, N.Y.: Random House Value Publishing.

Berger, R., \& McLeod, J. (2006). Incorporating nature into therapy: A framework for practice. Journal of Systemic Therapies, 25(2), 80-94.

Berman, M. G., Kross, E., Krpan, K. M., Askren, M. K., Burson, A., Deldin, P. J., . . Jonides, J. (2012). Interacting with nature improves cognition and affect for individuals with depression. Journal of Affective Disorders, 140(3), 300-305. doi:10.1016/j.jad.2012.03.012.

Berry, J. W., Poortinga, Y. H., Breugelmans, S. M., Chasiotis, A., \& Sam, D. L. (2011). Crosscultural psychology: Research and applications $\left(3^{\text {rd }}\right.$ ed.). Cambridge, UK: Cambridge University Press.

Bixler, R. D., \& Floyd, M.F. (1997). Nature is scary, disgusting, and uncomfortable. Environment and Behavior, 29(4), 443-467.

Boeve-De Pauw, J., \& Van Petegem, P. (2012). Cultural differences in the environmental worldview of children. International Electronic Journal of Environmental Education, $2(1), 1-11$. 
Britten, N. (2011). Qualitative research on health communication: What can it contribute? Patient Education and Counseling, 82(3), 384-388. doi: 10.1016/j/pec.2010.12.021.

California State Parks. (2005). Park and recreation trends in California 2005. Sacramento, CA: California State Parks.

Cameron, H. (2005). 'Asking the tough questions: A guide to ethical practices in interviewing young children'. Early Child Development and Care, 175(6), 597-610.

Canadian Parks and Recreation Association (2010). Reporting on the Pan Canadian Survey re: Children and Nature. Ottawa, ON.

Carver, A. Timperio, A., \& Crawford, D. (2008). Playing it safe: The influence of neighbourhood safety on children's physical activity-A review. Health \& Place, 14(2), 217-227.

Charles, C., Louv, R., Bodner, L., Guns, B., \& Stahl, D. (2009). Children and nature 2009: A report on the movement to reconnect children to the natural world. Santa Fe, NM: Children and Nature Network.

Chawla, L., \& Hart, R. A. (1995). The roots of environmental concern. NAMTA Journal, 20(1), 148-57.

Check, J., \& Schutt, R. K. (2012). Research methods in education. Thousand Oaks, CA: SAGE Publications.

Cheng, J. C., \& Monroe, M. C. (2012). Connection to nature: Children's affective attitude toward nature. Environment and Behaviour, 44(1), 31-49.

Clayton, S. (2007). Domesticated nature: Motivations for gardening and perceptions of environmental impact. Journal of Environmental Psychology, 27(3), 215-224. 
Clayton, S., \& Myers, G. (2009). Conservation psychology: Understanding and promoting human care for nature. Hoboken, NJ: Wiley-Blackwell.

Clements, R. (2004). An investigation of the state of outdoor play. Contemporary Issues in Early Childhood, 5(1), 68-80.

Collingridge, S. D., \& Gantt, E. E. (2008). The quality of qualitative research. American Journal of Medical Quality. 23(5), 389-395. doi: 10.1177/1062860608320646.

Creswell, J. W. (2009). Research Design: Qualitative, quantitative, and mixed methods approaches ( $3^{\text {rd }}$ ed.). Thousand Oaks, CA: SAGE Publications.

Derr, V., \& Lance, K. (2012). Biophilic Boulder: Children's environments that foster connections to nature. Children, Youth and Environments, 22(2), 112-143.

Dockett, S., \& Perry, B. (2005). Researching with children: Insights from the starting school research project. Early Child Development and Care, 175(6), 507-521.

Driessnack, M. (2009). Children and nature-deficit disorder. Wiley Periodicals, 14(1), 73-75.

Duerden, M. D., \& Witt, P. A. (2010). The impact of direct and indirect experiences on the development of environmental knowledge, attitudes, and behavior. Journal of Environmental Psychology, 30, 379-392.

Duschl, R. A., Schweingruber, H. A., \& Shouse, A. W. (Eds.) (2007). Taking science to school: Learning and teaching science in grades $K-8$. Washington, D.C.: National Academies Press. Retrieved from http://www.nap.edu/catalog.php?record_id=11625.

Einarsdóttir, J. (2007). Research with children: Methodological and ethical challenges. European Early Childhood Education Research Journal, 15(2), 197-211. 
Faber Taylor, A., \& Kuo, F. E. (2006). Is contact with nature important for healthy child development? State of the evidence. In C. Spencer, \& M. Blades. (Eds.), Children and Their Environments (pp. 124-140). Cambridge, U.K.: Cambridge University Press.

Faber Taylor, A., Kuo, F. E., \& Sullivan, W. C. (2001). Coping with ADD: The surprising connection to green play settings. Environment and Behavior, 33, 54-77. doi: $10.1177 / 00139160121972864$.

Fargas-Malet, M., McSherry, D., Larkin, E., \& Robinson, C. (2010). Research with children: Methodological issues and innovative techniques. Journal of Early Childhood Research, 8(2) 175-192.

Fischer, C. T. (2009). Bracketing in qualitative research: Conceptual and practical matters. Psychotherapy Research, 19(4-5), 583-590.

Fjørtoft, I. (2001). The natural environment as a playground for children: The impact of outdoor play activities in pre-primary school children. Early Childhood Education Journal, 29(2), $111-17$.

Flavell, J. H., Miller, P. H., \& Miller, S. A. (2002). Cognitive Development. Upper Saddle River, NJ: Prentice Hall.

Frankfort-Nachmias, C., \& Nachmias, D. (2008). Research Methods in the Social Sciences $\left(7^{\text {th }}\right.$ ed.). New York, NY: Worth Publishers.

Gardiner, H., \& Kosmitzki, C. (2011). Lives across culture: Cross-cultural human development (5th ed.). Boston, MA: Allyn \& Bacon.

Ghomeshi, J. (Host). (2013, May 8). CBC Radio Canada [Audio podcast]. Retrieved from http://www.cbc.ca/q/blog/2013/05/08/david-suzuki-on-why-kids-are-disconnected-fromnature/. 
Gill, T. (2007). No fear: Growing up in a risk averse society. London, UK: Calouste Gulbenkian Foundation.

Golafshani, N. (2003). Understanding reliability and validity in qualitative research. The Qualitative Report, 8(4), 597-607.

Hartig, T., Kaiser, F. G., \& Strumse, E. (2007). Psychological restoration in nature as a source of motivation for ecological behaviour. Environmental Conservation, 34(4), 291-299.

Healthy Canadians. (2013). Childhood obesity. Retrieved from http://healthycanadians.gc.ca/kids-enfants/obesity-obesite/risks-risques-eng.php.

Heerwagen, J. H., \& Orians, G. H. (2002). The ecological world of children. In P. H. Kahn, Jr., \& S. Kellert (Eds.), Children and nature: Psychological sociocultural and evolutionary investigation (pp. 29-63). Cambridge, MA: MIT Press.

Hennessy, E., \& Heary, C. (2005). Exploring children's views through focus groups. In S. Greene \& D. Hogan (Eds.), Researching children's experience: Approaches and methods. (pp.236-252). Thousand Oaks, CA: Sage.

Hofferth, S. L. (2009). Changes in American children's time -1997 to 2003. In Electronic International Journal of Time Use Research, 6(1), 26-47.

Hougie, D. P. (2010). Perspectives on Outdoor Recreation. Children, Youth and Environments, 20(2), 219-222.

Hyun, E. (2005). How is young children's intellectual culture of perceiving nature different from adults'? Environmental Education Research, 11(2), 199-214.

Irwin, L. G., and Johnson, J. (2005). Interviewing young children: Explicating our practices and dilemmas. Qualitative Health Research, 15(6), 821-831. 
Jackson, R. J., \& Tester, J. (2008). Environment shapes health, including children's mental health. Journal of the American Academy of Child \& Adolescent Psychiatry, 47(2), 129131.

Jahoda, M., Lazarsfeld, P. F., \& Zeisel, H. (2009). Marienthal: The sociography of an unemployed community ( $4^{\text {th }}$ ed.). New Brunswick, NJ: Transaction Publishers.

Jay, M., \& Schrami, U. (2009). Understanding the role of urban forests for migrants - uses, perception and integrative potential. Urban Forestry \& Urban Greening, 8, 283-294.

Johnson, Onwuengbuzie, \& Turner, (2007). Toward a definition of mixed methods research. Journal of Mixed Methods Research, 1(2), 112-133.

Kahn, P. H. Jr. (2002). Children's affiliations with nature. In P. H. Kahn, Jr., \& S. Kellert (Eds.), Children and nature: Psychological Sociocultural and Evolutionary Investigation (pp. 93-116). Cambridge, MA: MIT Press.

Kalvaitis, D., \& Monhard, R. M. (2012). The architecture of children's relationships with nature: A phenomenographic investigation seen through drawings and written narratives of elementary students. Environmental Education Research, 18(2), 209-227.

Kaplan, R., \& Kaplan, S. (2002). Adolescents and the natural environments: A time out? In P. H. Kahn, Jr., \& S. Kellert (Eds.), Children and nature: Psychological Sociocultural and Evolutionary Investigation (pp. 93-116). Cambridge, MA: MIT Press.

Kellert, S. R. (1996). The value of life: Biological diversity and human society. Washington, D.C.: Island Press.

Kellert, S. R. (2002). Experiencing nature: Affective, cognitive, and, evaluative development in children. In P. H. Kahn, Jr., \& S. Kellert (Eds.), Children and nature: Psychological Sociocultural and Evolutionary Investigation (pp. 117-151). Cambridge, MA: MIT Press. 
Kellert, S. R. (2005). Building for life: Designing and understanding the human-nature connection. Washington, D.C.: Island Press.

Kellert, S. R. (2008). Dimensions, elements, and attributes of biophilic design. In S. R. Kellert, J. H. Heerwagen, \& M. L. Mador (Eds). Biophilic design: The theory, science, and practice of bringing buildings to life. Hoboken, NJ: John Wiley \& Sons. Retrieved from http://books.google.ca/books?id=FyNer_nQrW4C\&printsec=frontcover\&source=gbs_ge _summary_r\&cad=0\#v=onepage \&q\&f=false.

Kellert, S. R., \& Wilson, E. O. (Eds.). (1993). The biophilia hypothesis. Washington, DC: Island Press.

Koskina, L. (2007-2013). Green fields. Public Domain Pictures. Retrieved from http://www.publicdomainpictures.net/view-image.php?image=27172\&picture=greenfields\&large $=1$.

Langston, A., Abbott, L., Lewis, V., \& Kellett, M. (2004). Early childhood. In S. Fraser, V. Lewis, S. Ding, M. Kellett, \& C. Robinson (Eds.), Doing research with children and young people (pp. 270-286). London, England: Sage.

Leitch, R. (2008). Creatively researching children's narratives through images and drawings. In P. Thomson (Ed.). (2008). Doing Visual research with children and young people (pp.3758). New York, NY: Routledge.

Lewis, J. R., \& Ozaki, R. (2009). Amae and Mardy: A comparison of two emotion terms. Journal of Cross-Cultural Psychology, 40, 917-934.

Louv, R. (2005). Last child in the woods: Saving our children from nature deficit disorder. Chapel Hill, NC: Algonquin Books 
Ma, H. (2009). Chinese Secondary school science teachers' understanding of the nature of science-Emerging from their views of nature. Res Sci Educ, 39, 701-724. doi $10.1007 / \mathrm{s} 11165-008-9100-2$.

Magrath, L. A. (2009). Narratives of nature: Television's storyline and preschool viewers' accounts (Unpublished master's thesis). Royal Roads University, Victoria, BC.

Maller, C. J. (2009). Promoting children's mental, emotional and social health through contact with nature: A model. Health Education, 109(6), 522-543.

Matthews, S. H. (2007). A window on the 'new' sociology of childhood. Sociology Compass 1, $322-334$.

Maudsley, M. (2007). Children's play in natural environments. London, UK: Children's Play Information Service.

Mayer, F. S., \& Frantz, C. M. (2004). The connectedness to nature scale: A measure of individuals' feeling in community with nature. Journal of Environmental Psychology, 24, $503-515$.

Miller, P. H. (2011). Theories of developmental psychology (5th ed.). New York, NY: Worth Publishers.

Mitchell, C., Theron, L., Smith, A., \& Stuart, J. (2011a). Picturing research: An introduction. In L. Theron, C. Mitchell, A. Smith, \& J. Stuart (Eds.). Picturing research: Drawing as Visual methodology (pp. 1-18). Rotterdam, Netherlands: Sense Publishers.

Mitchell, C., Theron, L., Stuart, J., Smith, A. \& Campbell, Z. (2011b). Drawings as research method. In L. Theron, C. Mitchell, A. Smith, \& J. Stuart (Eds.). Picturing research: Drawing as Visual methodology (pp. 19-36). Rotterdam, Netherlands: Sense Publishers. 
Nature. (1996). In Webster's Encyclopedic unabridged dictionary of the English language. New York, N.Y.: Random House Value Publishing.

Nisbet, E. K. L., Zelenski, J. M., \& Murphy, S. A. (2009). The Nature Relatedness Scale: Linking individuals" connection with nature to environmental concern and behaviour. Environment and Behavior, 41(5), 715-740.

Ozguner, H. (2011). Cultural differences in attitudes towards urban parks and green spaces. Landscape Research, 36(5), 599-620.

Pain, R. (2006). "Paranoid Parenting? Rematerialising Risk and Fear for Children." Social and Cultural Geography 7(2), 221-243.

Patton, M. Q. (2002). Qualitative evaluation and research methods (3rd ed.). Thousand Oaks, CA: Sage Publications.

Payne L. L., Mowen, A.J., \& Orsega-Smith, E. (2002). An examination of public parks preferences and behaviors among urban residents: The role of residential location, race and age. Leisure Sciences, 24(2), 181-198.

Penn, H. (2008). Understanding early childhood: Issues and controversies (2nd ed.). Berkshire, England: Open University Press.

Pergams, O. R. W., \& Zaradic, P. A. (2006). Is love of nature in the US becoming love of electronic media? 16-year downtrend in national park visits explained by watching movies, playing video games, internet use, and oil prices. Journal of Environmental Management, 80(4), 287-393.

Peters, K., Elands, B., Buijs, A. (2010). Social interactions in urban parks: Stimulating social cohesion? Urban Forestry \& Urban Greening, 9, 93-100. 
Petty, R. E., Wegener, D. T., \& Fabrigar, L. R. (1997). Attitudes and attitude change. Annual Review of Psychology, 48, 609-647.

Phenice, L., \& Griffore, R. (2003). Young children and the natural world. Contemporary Issues in Early Childhood, 4(2), 167-78.

Punch, S. (2002). Research with children: The same or different from research with adults? Childhood, 9(3), 321-341.

Rideout, V. J., Foehr, U. G., \& Roberts, D. F. (2010). Generation M2: Media in the lives of 8- to 18-year-olds. Menlo Park, CA: Kaiser Family Foundation.

Rideout, V. J., Vandewater, E.A., \& Wartella, E.A. (2003). Zero to Six: Electronic media in the lives of infants, toddlers and preschoolers. Menlo Park, CA: Kaiser Family Foundation.

Roberts, D. F., \& Foehr, U. G. (2008). Trends in media use. The Future of Children, 18 (1), 1137.

Rosenfeld, A. \& Wise, N. (2001). The overscheduled child: Avoiding the hyper-parenting trap. Griffin.

Roulston, K. (2011). Working through challenges in doing interview research. International Journal of Qualitative Methods, 10(4), 348-366.

Samuelsson, I. P., \& Pramling, N. (2009). Children's perspectives as ‘touch downs' in time: assessing and developing children's understanding simultaneously. Early Child Development and Care, 179(2), 205-216.

Shepardson, D. P. (2005). Student ideas: What is an environment? The Journal of Environmental Education, 36(4), 49-58. 
Skår, M., \& Krogh, E. (2009). Changes in children's nature-based experiences near home: From spontaneous play to adult-controlled, planned and organised activities. Children's Geographies, 7(3), 339-354. doi:10.1080/14733280903024506.

Smith, A., Duncan, J., \& Marshall, K. (2005). Children's perspectives on their learning: Exploring methods. Early Child Development and Care, 17(6), 473-487.

Statistical Office of the Slovak Republic. (2009). Urban Bratislava. Retrieved from http://app.statistics.sk/mosmis/eng/run.html.

Statistics Canada. (2012). Population of census metropolitan areas. Retrieved from http://www.statcan.gc.ca/tables-tableaux/sum-som/101/cst01/demo05a-eng.htm.

Strife, S. (2008). The concrete jungle: Environmental awareness and experiences of nature among urban children. (Unpublished doctoral thesis). University of Colorado, Boulder, United States.

Turner, W. R., Nakamura, T., \& Dinetti, M. (2004). Global urbanization and the separation of humans from nature. Bioscience, 54(6), 585-590.

Ulrich, R. S. (1984). View through a window may influence recovery from surgery. Science, $224,420-421$.

United Nations Convention on the Rights of the Child (UNCRC). (1989). Convention on the Rights of the Child. London, UK. Retrieved from http://www.ohchr.org/en/professionalinterest/pages/crc.aspx.

Unsworth, S. J., Levin, W., Bang, M., Washinawatok, K., Waxman, S. R., \& Medin, D. L. (2012). Cultural differences in children's ecological reasoning and psychological closeness to nature: Evidence from Menominee and European American children. Journal of Cognition \& Culture, 12, 17-29. doi:10.1163/156853712X633901 
Van de Vijver, F., \& Chasiotis, A. (2010). Making methods meet: Mixed designs in crosscultural research. In J. A. Harkness, M. Braun, B. Edwards, T. P. Johnson, L. Lyberg, P. P. Mohler, B. E. Pennell, \& T. W. Smith (eds.). Survey methods in multinational, multiregional, and multicultural contexts (pp. 455-473). Hoboken, N.J.: Wiley.

Veale, A. (2005). Creative methodologies in participatory research with children. In Greene, S. \& Hogan, D. (Eds.). Researching Children's Experiences: Methods and Approaches (pp. 252-272). London: Sage.

Vining, J., Merrick, M. S., \& Price, E. A. (2008). The distinction between humans and nature: Human perceptions of connectedness to nature and elements of the natural and unnatural. Human Ecology Review, 15(1), 1-11.

Wells, N. M., \& Lekies. K. S. (2006). Nature and the life course: Pathways from childhood nature experiences to adult environmentalism. Children, Youth and Environments, 16(1), 1-24.

Wilson, E. O. (1984). Biophilia. Cambridge, MA: Harvard University Press.

Wridt, P. J. (2004). An historical analysis of young people‘s use of public space, parks, and playgrounds in New York City. Children and Environments, 14(1), 86-106. 